AROUEOLOGÍA Y SOCIEDAD

№ $25,2012: 35-56$

ISSN: $0254-8062$

RECIBIDO: AGOSTO DE 2012

ACEPTADO: OCTUBRE DE 2012

\title{
SACRIFICIO DE CÓNDOR (VULTUR GRYPHUS) EN EL FORMATIVO TARDÍO DE CERRO PUNTA BLANCA, VALLE DE LURÍN, PERÜ
}

\author{
NOÉ JAVE CALDERÓN \\ Arqueología y Medio Ambiente. Proyecto Aroueológico Atocongo Norte \\ apunoe@yahoo.com
}

\section{RESUMEN}

En el año 2006 se descubrió la osamenta parcial de dos cóndores machos y adultos, con evidencia de marcas de corte y huellas de fracturas postmortem que provienen de contextos arqueológicos de la mina de cal prehispánica del período formativo tardío de Cerro Punta Blanca (300-100 a.C.), ubicado en las lomas costeras de Jatosisa, valle de Lurín, Perú. De estos esqueletos, uno fue hallado casi completo y otro de manera parcial. El primero, asociado a un fragmento de cerámica que representa la cabeza de una «serpiente encrespada». Esta asociación nos remite al mito de la transformación de la serpiente en cóndor existente desde los períodos Arcaico y Formativo, representado en los petroglifos, flautas de hueso y tejidos, así como su registro en relatos etnohistóricos y representaciones astronómicas. El presente estudio confirma la importancia del cóndor en los contextos rituales de los habitantes de lomas desde hace dos milenios.

PalABRAs ClAVE: Sacrificio de cóndor, zooarqueología, cal, Formativo Tardío, valle de Lurín, arqueología cognitiva, lomas.

\section{Abstract}

In 2007 we found same partial skeletal of two Andean condors with evidence of cut marks and fractures postmortem in archaeological context of lime exploitation during the period Late Formative site of Cerro Punta Blanca (300-100 b.C.), it is located at lomas of Jatosisa, Lurin valley, Peru. These bones were associated to a head of snake of pottery. This association permitted us to relation to myth of transformation the snake to condor seen in petroglyphs, bone flutes and textiles of Archaic and Formative period and registered in etnohistorical dates and astronomic representations. This study confirms the importance of condor in Andean ritual context of inhabitants of green hills since two millenniums ago.

KEYwORDS: Condor sacrifice, zooarchaeology, lime, Late Formative, Lurin valley, cognitive archaeology, green hills.

* El análisis osteológico fue efectuado en su totalidad por el Dr. Alfredo Altamirano Enciso, docente de la Universidad Nacional Mayor de San Marcos y de la Universidad Nacional Federico Villarreal.

zooarqueologo@hotmail.com 
«El cóndor, animal sagrado desde las más remotas culturas hasta nuestros días, es motivo de gran reverencia. Todo cuanto a él pertenece: plumas, uñas, pico, hueso, etc. Se considera lleno de poder y se guarda con mucho respeto. Las flautas que se hacen con sus huesos son tenidas en mucho. Otras aves de presa (halcón, águila, cernícalo) gozan también de particular estima; mas nunca alcanzan el rango que detenta el cóndor»

(Jiménez Borja 2009 [1951]: 72)

\section{INTRODUCCIÓN}

En el área andina, los cóndores están profusamente representados tanto en la iconografía como en la mitología (Tello 1932, 1967; Yacovleff 1932; Carrión Cachot 1959; Bird 1964; Kauffmann 1973; Hocquenghem 1986; Bueno 1997, 2006; Shady et al. 2004, 1999; Lumbreras 2007; Millones et al. 2012; entre otros), sin embargo, hasta la fecha no se había descrito sus evidencias zooarqueológicas contextualizadas, excepto el caso correspondiente a periodos más tardíos (Maita y Casareto 2012). Este artículo concierne al hallazgo de restos óseos de dos cóndores recuperados durante las excavaciones arqueológicas de Cerro Punta Blanca en la segunda campaña de excavaciones ejecutadas en los años 2006-2007. El contexto del cóndor casi completo fue encontrado en una estructura circular semisubterránea de 1,80 m de diámetro en promedio y una profundidad que oscila entre 0,80-0,85 m. Estas estructuras circulares se lograron a partir de la transformación de los piques mineros a cistas o tumbas. Los piques mineros confirman la existencia de un yacimiento de explotación de cal, la que afloró en tiempos geológicos en forma de lechadas y emulsiones. Este producto fue ampliamente utilizado en el antiguo Perú para el chacchado de coca tanto por grupos locales cuanto foráneos.

El análisis del material óseo de animales del sitio Cerro Punta Blanca, realizado entre enero de 2011 y marzo de 2012, da cuenta de alrededor de doce mil fragmentos óseos, determinándose la presencia de camélidos sudamericanos, cérvidos, roedores, aves andinas, batracios, zorros, perros e incluso animales modernos como vacunos y caprinos hallados en las capas superficiales. Entre las aves identificadas tenemos las gallináceas o perdices (Nothoprocta pentlandii), Anatidae o pato joque (Cairina moschata), aynos o huashuas (Fulica ardesiaca), urpichas o pajaritos diversos (Passeriformes), gaviotas (Larus welcheri), Strigidae o lechuzas (Buho virginianus), pingüinos (Spheniscus humboldti) y cóndores (Vultur gryphus), dando motivo este último al presente artículo. Sin embargo, el estudio de la avifauna arqueológica andina había sido descuidado (Rea 1986; Vásquez \& Rosales 1999; Lumbreras 2007; Goepfert 2008; Maita \& Casaretto 2012). ${ }^{1}$

Para realizar este análisis hemos empleado el método de la anatomía comparada de vertebrados, contrastando las piezas óseas modernas con los fragmentos antiguos y apoyándonos en las guías osteológicas conocidas (Málaga et al. 1976; Altamirano 1979, 1983, 1995; Adaro et al. 1993; Baumel et al. 1993; Vásquez et al. 1999; Mameli 2003).

\section{LOCALIZACIÓN}

El sitio se localiza en la margen izquierda del río Lurín, a $5 \mathrm{~km}$ al Este del pueblo actual de Pachacamac, provincia y departamento de Lima. La cima tiene una altitud de 639,50 m y en su base $439 \mathrm{~m}$ de altitud. Ecológicamente forma parte de las lomas de Jatosisa (Fig. 1).

En la zona de Cerro Punta Blanca se encuentran localmente unidades litológicas como la formación Herradura y Atocongo, ambas de naturaleza calcárea y de la era mesozoica.

1 En el mundo hay aproximadamente 8.700 especies correspondientes a la clase aves, distribuidas en 25 órdenes y aunque ciertos ornitólogos apuntan que su número todavía es mayor. La principal concentración de estas se da en Sudamérica, donde se han contabilizado en la actualidad aproximadamente unas 2.930 especies vivas (Mameli 2003). 


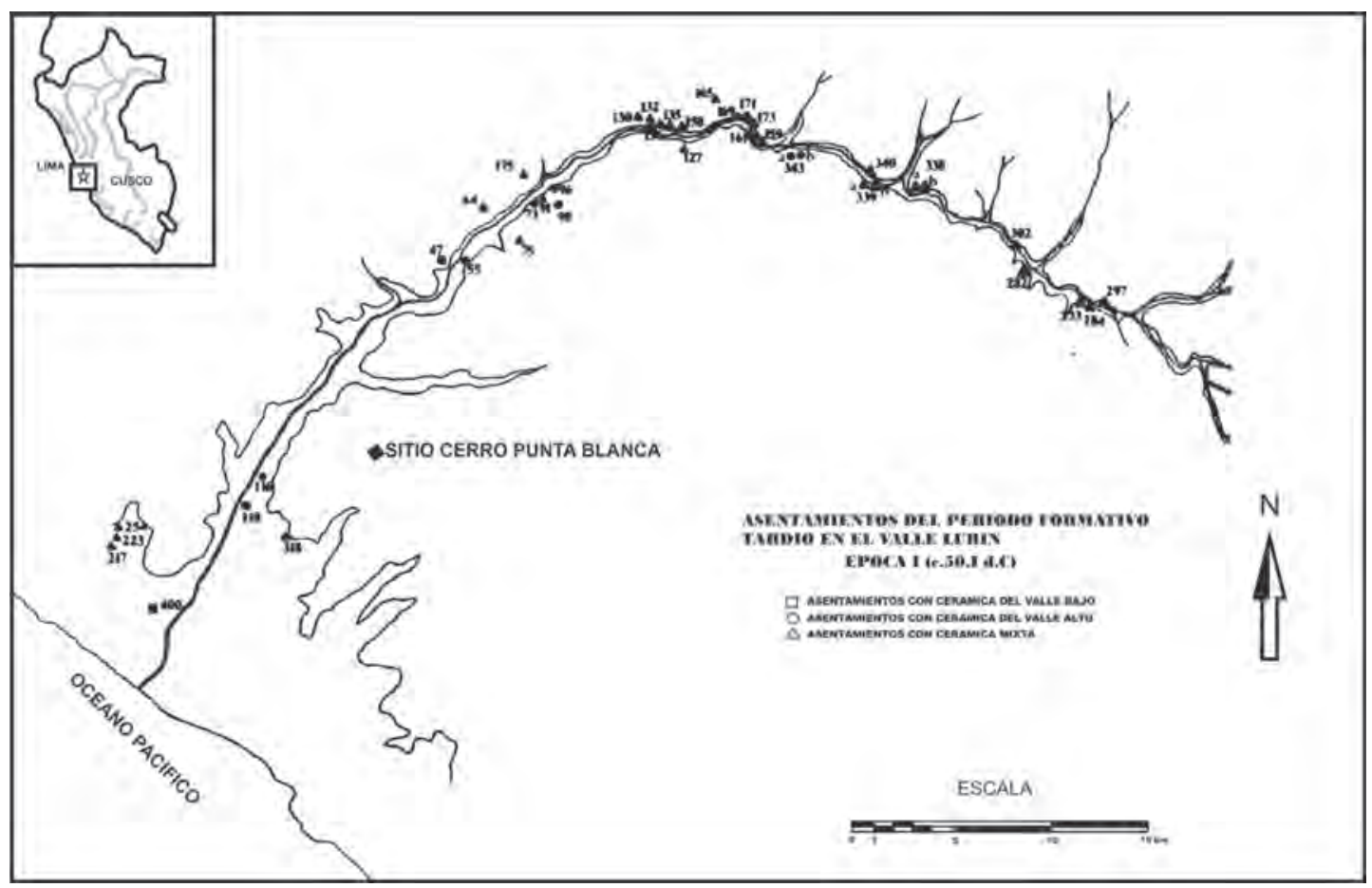

Figura 1. Localización del sitio Cerro Punta Blanca en el contexto de los sitios arqueológicos coetáneos en el valle de Lurín, ubicados por T. Patterson et al. (1982) que considera como la época 1 del período Intermedio Temprano.

El área de lomas², en la estación de invierno presenta vegetación densa, compuesta por hierbas, arbustos típicos, amancaes, taras, mitos, tomates y papas silvestres. En el año 2011, entre junio y noviembre, este ecosistema se reactivó una semana y se desecó rápidamente en un mes. En verano, la vegetación se seca bruscamente formando un ambiente yermo por lo que la yesca permanece raquítica e inicia el proceso de pedogénesis de un suelo húmico de lomas muy fértil que se reactiva con el inicio de la estación invernal del siguiente año, permitiendo el resurgimiento de todo el banco polínico en una secuencia de poblaciones vegetales de menor a mayor tamaño que sólo se reproduce en este ecosistema frágil de vegetación xerofítica donde proliferan las vizcachas, roedores, lechuzas, serpientes, águilas, algunas arañas, escorpiones y otros insectos (Fig. 2).

En el periodo Formativo hubo mayor concentración de humedad entre las Lomas de Atocongo por el Norte hasta Chilca por el Sur, por lo que la fauna de guanacos (Lama guanicoe), venados (Odocoileus virginianus), perdices (Nothoprocta pentlandii), aves de lomas y mar, vizcachas (Lagidium peruanum), batracios (Bufo sp.) y roedores pequeños o ukush (Cricetidae) se encuentran con frecuencia en los contextos arqueológicos.

El análisis de la cerámica de Punta Blanca indica la existencia de formas de cuencos de pasta naranja, botellas de doble pico y tronco-cónicos, ollas de labios ligeramente protuberantes, engobe rojo oscuro, pintura roja y picos cónicos. Estos cuencos y escudillas muestran paredes inferiores ligeramente convexas y las paredes superiores con una pronunciada inclinación hacia el exterior con ángulo basal, pareciéndose

2 Terreno de quebradas y cerros localizado entre 300 y 600 msnm muy cerca de la zona litoral costera. En verano es seco y en invierno se cubre de una densa vegetación. Es un fenómeno natural típico de la costa peruana y del Norte de Chile. Ha sido un piso ecológico importante para los cazadores, recolectores, mineros, agricultores y chamanes del mundo andino (Brack 1974, 1988; Oka y Ogawa 1984; Pulgar Vidal 1987; Rostworowski 1981). 


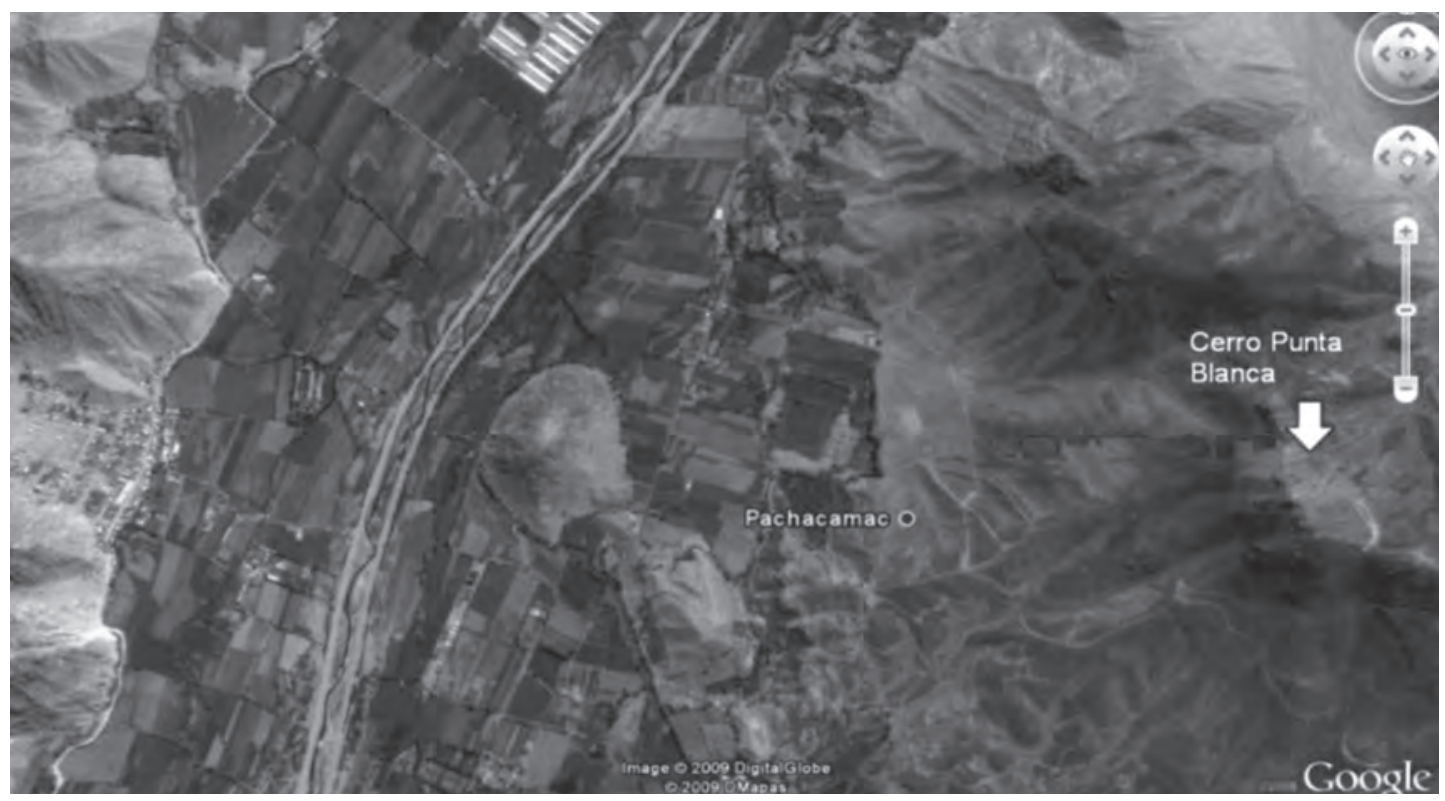

Figura 2. Localización del sitio Cerro Punta Blanca, a $5 \mathrm{~km}$ al Este de Pachacamac.

a la cerámica de Villa El Salvador, El Panel y Tablada de Lurín que se caracteriza por las vasijas zoomorfas de felinos y serpientes (Stothert 1980; Bueno 1982; Paredes 1984; Cárdenas 1999; Maguiña y Paredes 2009). La figurina de cerámica que representa a la «serpiente encrespada» fue hallada en asociación con las osamentas de los cóndores de Punta Blanca y guarda similitud con la alfarería del Panel, indicando la contemporaneidad de estos sitios (Ramos 2008). Los entierros humanos primarios se hallan en fosas de piedra subangulares en posición sedente y también de cúbito lateral también son característicos de los cuatro sitios ya mencionados. La introducción de ídolos de cerámica de la fase Huayco de la secuencia de Huachipa del valle del Rímac confirma la ocupación del sitio entre 300 y 100 a.C. que corresponde al periodo Formativo Tardío dentro de la tradición Blanco sobre Rojo (Palacios 1988, 2004).

\section{EL CONTEXTO ARQUEOLÓGICO}

El contexto arqueológico del cóndor y la figurina zoomorfa de cerámica de serpiente fue hallado en el pique minero $\mathrm{N}^{\circ} 6$ de la Unidad F2, Sector II y Capa C, y excavado por el arqueólogo Max Salazar Vivanco el 6 de marzo de 2007. Este pique tiene forma cilíndrica y ligeramente troncocónico hacia la base, boca redondeada y se ubica al lado norte del Estructura Circular № 8 . La superficie de la estructura estaba cubierta por piedras medianas subangulares y suelo de loma. Su contenido está compuesto de cal, tierra fina de loma, piedras y cascajo, de consistencia suelta, deleznable y color beige claro. La capa C, constituye la mayor parte del relleno, y al realizarse la limpieza, se observa que las piedras angulares, a modo de locetas, están superpuestas unas sobre otras y entrecruzadas de manera sistemática a modo de un piso sellador (Fig. 3).

La mayor parte del relleno está constituido por la denominada Capa C, en tanto que las capas A y B son relativamente superficiales. La capa C está conformada por material cerámico, lítico, óseo y malacológico. La cerámica se presenta en forma de fragmentos de vasijas utilitarias con huellas de uso como restos de quema en su interior y hollín en su superficie. Los tiestos corresponden a botellas, cántaros, escudillas, cuencos, ollas y tazones. El material lítico se conforma de boleadores manuports y manos de moler. Los restos óseos corresponden a camélidos, cérvidos y aves de lomas, en especial perdices. Los restos malacológicos pertenecen a valvas de choros (Aulacomyia ater y Choromytilus chorus), pata de burro (Concholepas concholepas) y caracoles de loma (Scutalus sp. y Bulimulidae). 


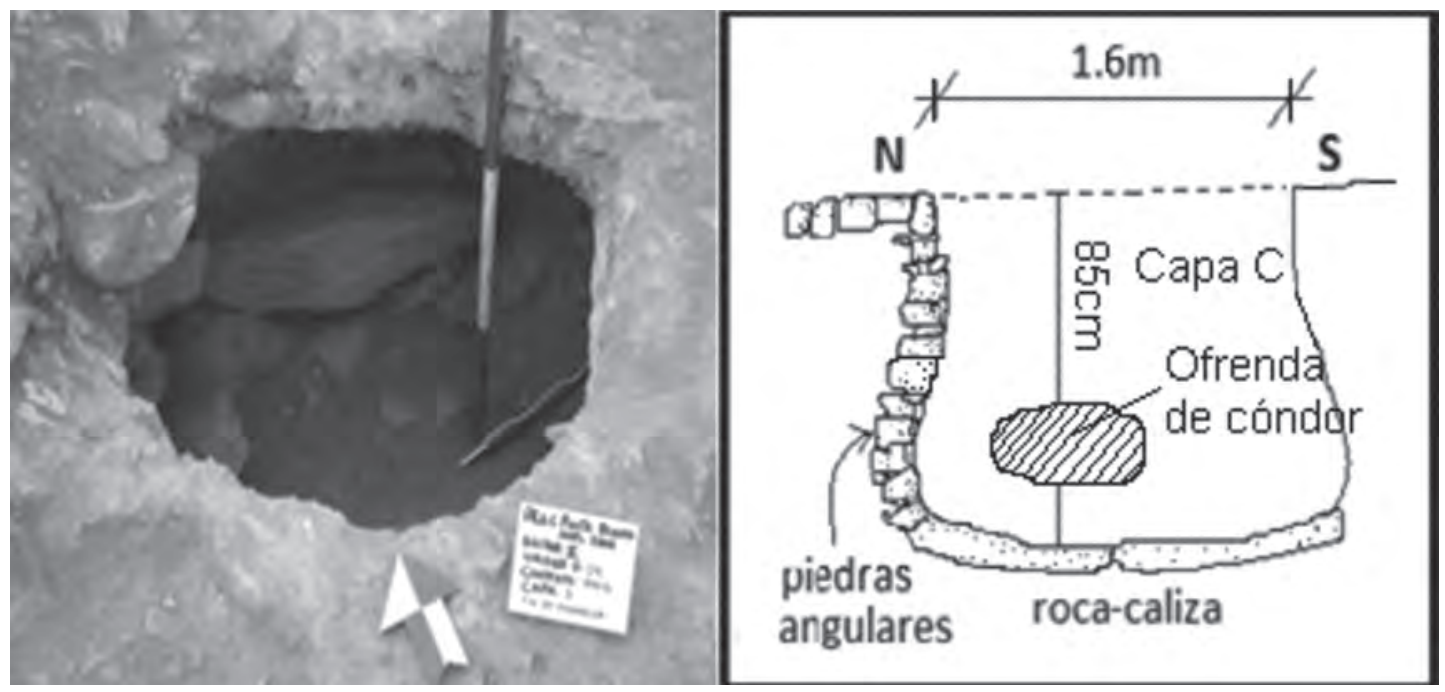

Figura 3. Planta y perfil del Pique Minero $N^{\circ}$ 6, excavado en 2007.

Las paredes Oeste y Sur del pique minero presentan revestimiento parcial con piedras angulares y canteadas, medianas y pequeñas, unidas con argamasa de tierra (barro), formando facetas más o menos regulares. Ambos revestimientos fueron rematados en la boca con una hilera de piedras angulares. El espacio interno es de forma tubular ligeramente expandido en la base hacia el lado Este. Se observan pequeñas cavidades en la base, acumulándose con mayor intensidad en la parte Este. Aparentemente este revestimiento quedó inconcluso. La capa D está dada por la roca de piedra-caliza. Por la disposición de estos revestimientos y el contexto arqueológico podemos inferir que este pique estaba siendo utilizado como un área de extracción de caliza y procesamiento de cal, y luego, en su abandono, se depositó el contexto ritual del cóndor (Fig. 4).

A 0,85 m de profundidad se recuperó el hallazgo № 213, el cual es un fragmento de una figurina de cerámica reutilizada, al parecer era parte de una escudilla, en cuyo borde se representa una serpiente de ojos globosos o hinchados, con nariz fina y alargada, boca prominente (¿sonriente?) con dientes en serie continua y en cuyo dorso sobresale dos crestas triangulares, romas y contorneadas por bandas de pintura roja, finas y sinuosas. Por la curvatura de estas bandas es posible inferir que las crestas formaban parte del cuerpo de la vasija. La boca exhibe un ennegrecido producto de defecto de cocción. Debajo del hallazgo continua la misma matriz de relleno, cubierta por tierra y cascajo hasta la base de la estructura (Figs. 5 y 6).

Figura 4. Ampliación del contexto del pique minero $n^{\circ} 6$, indicando el lugar donde se halló el esqueleto del cóndor.

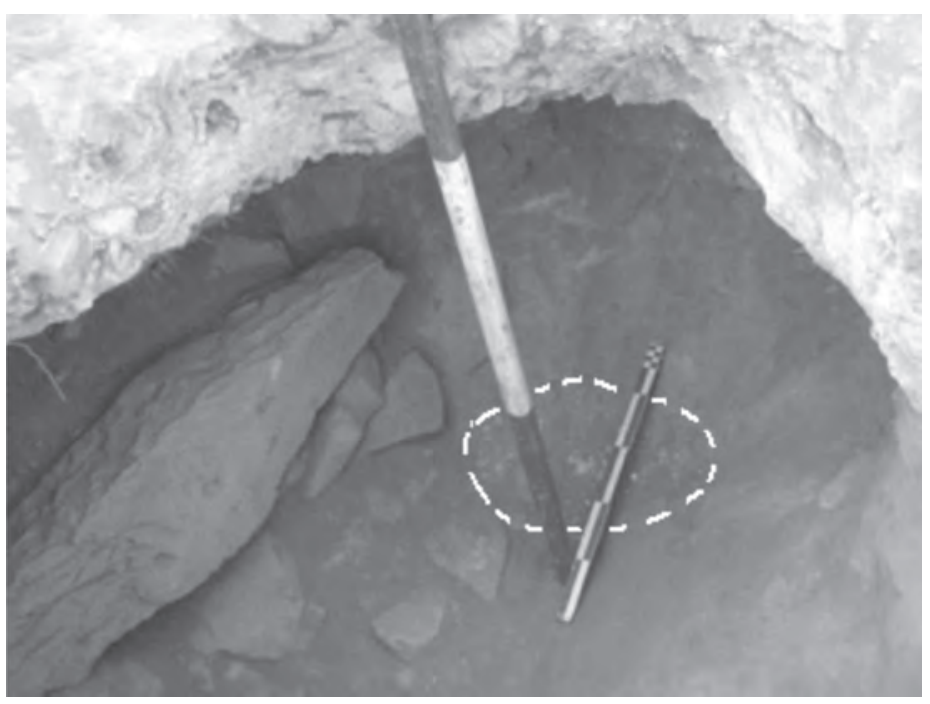




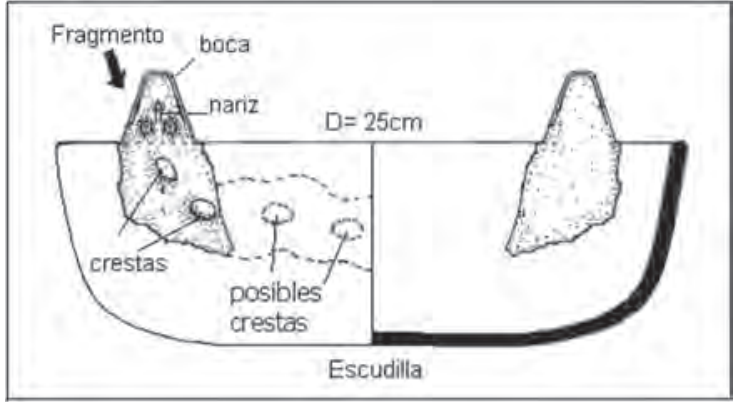

Figura 5. Reconstrucción del cuenco fracturado con la figura de la serpiente sonriente y encrestada.

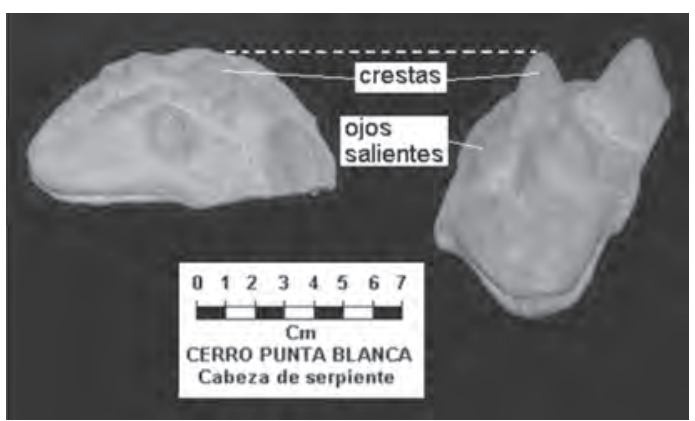

Figura 6. Hallazgo $N^{\circ} 213$, Figurina de cerámica reutilizada de la serpiente sonriente, asociada al esqueleto del cóndor en el pique minero $N^{\circ} 6$.

\section{Metodología}

La totalidad de la excavación comprendió 98 unidades de 10 x 10 m, distribuidos en cuatro sectores (I, II, III y IV) donde se han descubierto piques mineros, pozos circulares funerarias, cistas, templetes, áreas domésticas y áreas de molienda, entre otros.

Los huesos de animales han sido analizados utilizando la anatomía comparada y el enfoque biocultural (biológico y cultural) que consiste en contrastar los fragmentos óseos antiguos con esqueletos modernos, permitiéndonos identificar el género, especie, tipo de hueso, lado, edad y sexo. Por el ámbito cultural se ha dado énfasis a las prácticas culinarias, el tipo de matanza, las fracturas, el patrón de descuartizamiento y la distribución de carnes. Esto se obtiene describiendo los tipos de fracturas: longitudinal, transversal y concoidal, así como la coloración del periostio (White 1953).

Un tercer aspecto ha sido dado por las características post-deposicionales de los huesos (tafonomía). Por su asociación a la cal pulverulenta, los huesos depositados en el contexto arqueológico han sufrido un conjunto de fracturas postmortem y erosión del periostio, lo que a su vez, ha permitido la preservación de la mayor parte del material óseo al haber creado un ambiente seco que evitó los impactos de la humedad de la loma. Los datos cualitativos de cada hueso y descripciones óseas han sido realizados en fichas de investigación y el conjunto de esta información nos permitió también contabilizar la frecuencia de restos óseos por especies y edades.

Para la determinación de la edad de los cóndores, a través de los huesos, hemos utilizado el patrón general de edad en animales conocido como tierno, joven y adulto, observable en la fusión de las epífisis de los huesos largos, así como el grado de porosidad que exhiben estos huesos en la estructura interna de las epífisis (Wing 1972). Así, las aves tiernas no presentan fusión de las epífisis proximales ni distales y hay cartílagos de unión con la diáfisis, los jóvenes exhiben la línea de fusión y de textura porosa en sus extremidades articulares y en los adultos, estas líneas de fusión se encuentran soldadas (Mameli 2003).

Para la determinación del sexo de los vultúridos también hemos seguido el patrón general de la estructura ósea de animales que define que los machos exhiben mayor rugosidad ósea debido a las fuertes inserciones musculares y adquieren mayor estatura. En cambio, las hembras posee superficies óseas lisas y son de menor estatura que los machos. Así, el peso de los cóndores machos adultos oscila entre 12 kilos a más y las hembras hasta 10 kilos. Estas aves presentan un marcado dimorfismo sexual observable en los huesos. En casos de huesos aislados, las medidas para las epífisis de huesos largos sirve como método comparativo, siguiendo las pautas de Howard (1968), Gisela Von den Driesch (1976) y Vásquez y Rosales (1999). Estas medidas fueron tomadas de la epífisis distal del húmero entre el epicóndilo medial y el epicóndilo lateral. 
El cóndor es el animal volador de mayor tamaño que existe en la actualidad en el mundo. El adulto exhibe una estatura que oscila entre 1,20 a 1,30 m, cuya envergadura alar alcanza hasta 3,30 m. El macho tiene una cresta carnosa de color rojizo oscuro y una carúncula (pliegue carnoso) que cuelga del cuello. El iris del ojo es café. La hembra tiene un plumaje idéntico al del macho, pero carece de cresta y su iris es rojo. Los juveniles de ambos sexos son de coloración general pardo-grisácea y la cabeza y cuello de piel negruzca, con collar café. Paulatinamente, en un lapso de seis años, adquieren el plumaje negro típico de los adultos. El cóndor puede llegar a vivir hasta 75 años, siendo una de las aves más longevas del planeta (Koepcke 1970; Haemig 2005; Klemenc 1997; Fjeldsa y Krabbe 1990).

\section{DESCRIPCION DE LOS HUESOS}

Los huesos de cóndores han sido hallados en las temporadas de 2004 y 2006-7, procedente de los piques mineros y cistas en los sectores II y III; en este artículo damos cuenta del contexto № 78, habiéndose identificado restos muy parciales de otros tres cóndores. Veamos esta descripción en la Tabla 1.

\begin{tabular}{|c|l|c|l|}
\hline $\begin{array}{c}\text { Bolsa } \\
\mathbf{N}^{\circ}\end{array}$ & \multicolumn{1}{|c|}{ Localización } & \multicolumn{1}{|c|}{ Edad } & \multicolumn{1}{c|}{ Descripción } \\
\hline 13 & $\begin{array}{l}\text { Unidad D-12, } \\
\text { contexto E.C. } \\
\mathrm{N}^{\circ} \text { 12, Capa C } \\
\text { (15/02/2007) }\end{array}$ & $\begin{array}{c}\text { 1 cóndor adulto, entie- } \\
\text { rro parcial y posible- } \\
\text { mente macho }\end{array}$ & $\begin{array}{l}\text { 6 fragmentos de 2 tibias robustas, 2 metatarsos } \\
\text { y 2 peroné, lado izquierdo, diáfisis fracturados } \\
\text { postmortem y quemado. }\end{array}$ \\
\hline 57 & $\begin{array}{l}\text { Sector III Unidad } \\
\text { J-14, 5C. 2, Capa } \\
\text { B, estructura 11 } \\
(19 / 07 / 2004) .\end{array}$ & $\begin{array}{c}\text { 1 cóndor adulto, entie- } \\
\text { rro parcial }\end{array}$ & $\begin{array}{l}\text { 1 epífisis proximal de cúbito derecho con fractura } \\
\text { postmortem, parte del ala derecha asociada a con- } \\
\text { texto funerario. }\end{array}$ \\
\hline 78 & $\begin{array}{l}\text { Sector II, Unidad } \\
\text { F-12, } \\
\text { contexto P.M. 6, } \\
\text { capa C } \\
(05 / 03 / 2007) .\end{array}$ & 2 cóndores adultos & $\begin{array}{l}\text { 85 fragmentos y huesos completos y robustos. } \\
\text { NMI=2 individuos machos. Un húmero con } \\
\text { infección articular. Este material es motivo del } \\
\text { presente artículo (Ver tabla 2 y Fig. 6). }\end{array}$ \\
\hline 152 & $\begin{array}{l}\text { Sector II Unidad } \\
\text { H-13, Contexto } \\
\text { P.M.10, capa C } \\
(17 / 01 / 2007) .\end{array}$ & 1 cóndor adulto & $\begin{array}{l}\text { 1 vértebra cervical, 1 tibia y 1 peroné completos } \\
\text { con ligeras fracturas postmortem en la faceta arti- } \\
\text { cular. La tibia tiene infección en la epífisis proxi- } \\
\text { mal en su área articular. Exhibe fractura en área } \\
\text { lateral del peroné por uso de Liwi. }\end{array}$ \\
\hline
\end{tabular}

Tabla 1.- Relación de bolsas y contextos donde se han registrado huesos de cóndores (Vultur gryphus).

En la bolsa 78 se han registrado los huesos de dos cóndores adultos y robustos, uno adultojoven y otro viejo. La superficie de los huesos presenta una coloración blanquecina debido al efecto de la cal. En la reconstrucción del entierro parcial del individuo adulto se aprecia la ausencia de las garras y pico (Fig. 7). La verificación del hallazgo de dos epífisis distales de húmeros derechos, cuyo ancho de esta porción ósea es de $47 \mathrm{~mm}$ y otro de $46 \mathrm{~mm}$, que indica robustez propia del género masculino. El cóndor viejo presenta mayor cantidad de micro porosidades en la región articular debido a una patología artrítica (Fig. 8). El metacarpiano izquierdo completo con longitud de 14,2 $\mathrm{cm}$, con porosidades en áreas articulares similar al húmero adulto. El fémur en la parte posterior y proximal hasta la metáfisis superior exhibe una pequeña acumulación de material orgánico, probablemente se trata de restos de hojas de coca (Erytroxilon novogranatense) masticados y adheridos al periostio en un área de $28 \times 25 \mathrm{~mm}$.

Hay dos marcas de cortes profundos, que han dejado una impronta en forma de U, en el área articular de la epífisis proximal del húmero derecho, seguidos de fracturas laterales antiguas (Fig. 9) y también se presentan otras marcas superficiales en el borde superior del mismo hueso ejecutado con un cuchillo lítico (Fig. 10). Esta inferencia se confirmaría con el hallazgo de una punta de obsidiana de 


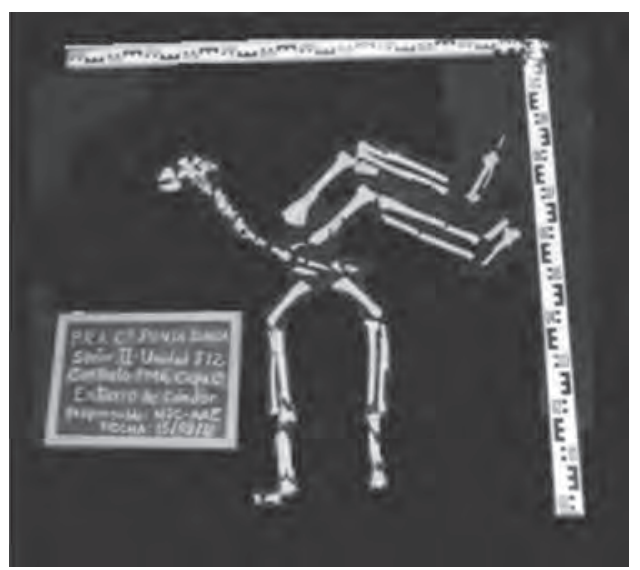

Figura 7. Entierro de cóndor (Vultur gryphus) de Cerro Punta Blanca, bolsa 78.

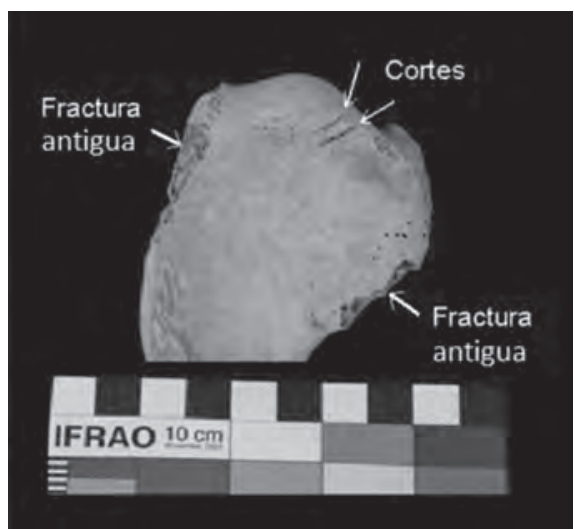

Figura 9. Húmero derecho de cóndor adulto y robusto con dos marcas de corte profundos en el área articular proximal y fracturas postmortem a ambos lados de la articulación principal para el descuartizamiento.

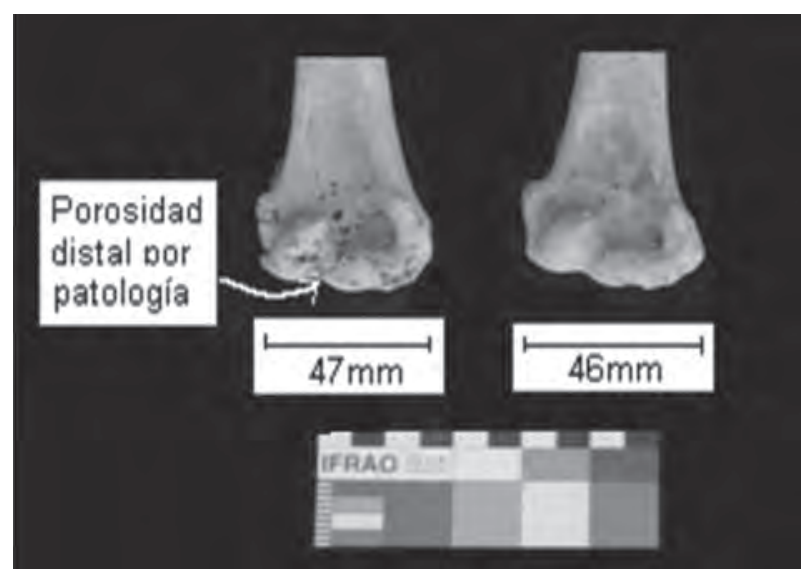

Figura 8. Epífisis distales de húmeros derechos de dos cóndores del mismo contexto.

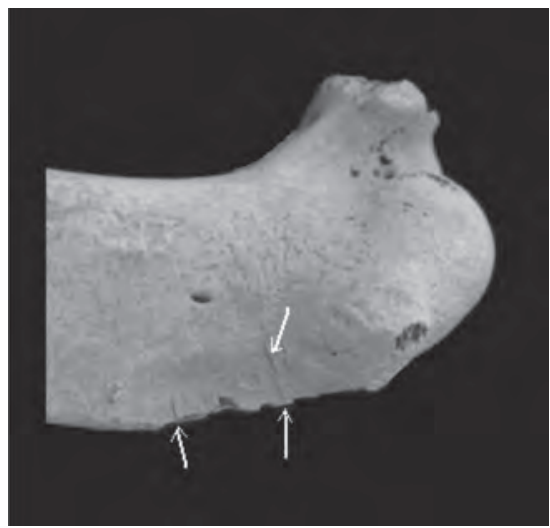

Figura 10. El mismo húmero exhibe marcas de cortes superficiales en el borde superior.

$4 \mathrm{~cm}$ de longitud, hallado en el sector II, Unidad F-12, contexto de la estructura circular № 3, capa C y asociado a huesos de cérvidos. Asimismo, las incisiones dejadas por objetos filudos en el periostio de huesos presentan una hendidura característica en forma de «U», en cambio, cuando son mordedura de roedores dejan improntas en forma de «V» a nivel superficial (Mameli 2003: Fig. 31).

Las fracturas postmortem de arrancamiento se caracterizan por tener pequeñas ondulaciones y de superficie porosa, localizadas en las áreas rugosas para las inserciones musculares y presentando una coloración semejante al periostio debido a su antigüedad. La epífisis proximal, cabeza y trocánter mayor de ambos fémures también fueron fracturados, así como en otras áreas articulares, lo que indica la intensidad de la fuerza utilizada al desmembrar estas partes corporales (Fig. 11).

Otro tipo de fractura postmortem que aparece en las diáfisis del húmero, cubito, radio, fémur y tibia se caracteriza por su astillado y de color blanquecino, el cual podemos considerar que es producto de la fragilidad ósea por causa de meteorización (tafonómica) y que ha ocurrido durante la excavación y/o transporte (Fig. 12). 


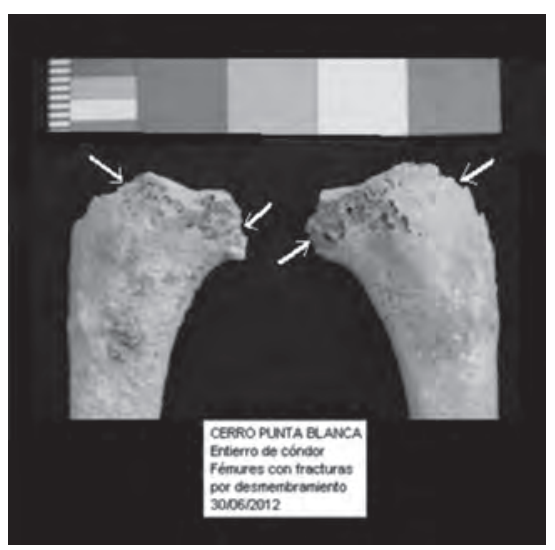

Figura 11. Fémures ligeramente fracturados en sus epífisis, indicando violencia postmortem en su articulación.

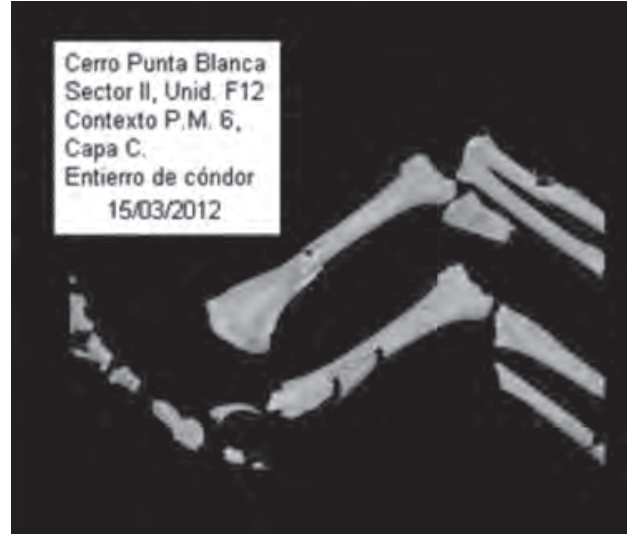

Figura 12. Fémures severamente fracturados en sus epífisis proximales. La cabeza y trocánter mayor (flechas) indican la violencia postmortem para desmembrar las piernas de su articulación. Obsérvese la pátina de cal que cubre el periostio.

Por otro lado, también existe patina de color negro que cubre partes del periostio de los huesos largos como indicador del crecimiento de hongos xerofíticos y presencia de líquenes de lomas por acción de humedad de los meses de invierno, esto indicaría que la cal no logró proteger totalmente el esqueleto del ave. Además, los factores del clima húmedo y seco nos confirman que el proceso tafonómico atravesaba por la fase de diagénesis, debido a su localización en el área de lomas, contribuyendo decisivamente para la fragilidad de los restos óseos y produciendo las fracturas postmortem, principalmente en las áreas de las diáfisis. Para el cálculo del NISP (Número de especímenes óseos) y NMI (Número Mínimo de Individuos), los huesos de cóndores han sido clasificados por partes corporales, registrándose la frecuencia de huesos (Tabla 2).

\begin{tabular}{|l|c|c|}
\hline \multicolumn{1}{|c|}{ Partes corporales } & NISP & NMI \\
\hline Cráneo y Mandíbula & 6 & 1 \\
Vértebras & 17 & 1 \\
Pelvis & 3 & 1 \\
Costillas & 1 & 1 \\
Húmeros & 5 & 2 \\
Coracoides & 7 & 1 \\
Metacarpianos & 5 & 1 \\
Fémures & 5 & 1 \\
Tibias y peroné & 6 & 1 \\
Diáfisis de tibias & 2 & 1 \\
Tarsometatarsos & 5 & 1 \\
Accesorios & 14 & 2 \\
Huesos largos diversos & 85 & 2 \\
\hline \multicolumn{2}{|c|}{ Total } & 14 \\
\hline
\end{tabular}

Tabla 2.- Relación de huesos de cóndores del contexto arqueológico bajo estudio, Bolsa 78.

Para definir el diagnóstico diferencial del caso del cóndor, este podría haberse confundido con un suri o ñandú, harpía o águila pescadora debido a la ausencia del pico y las garras, empero la robustez de sus huesos, las pequeñas callosidades formadas en hilera en el periostio de los radios y cúbitos (de las alas) en una distancia de 10 a $12 \mathrm{~mm}$ para la inserción del músculo coracobraquial para la actitud 
del vuelo nos indican que estábamos ante un vultúrido (Baumel et al. 1993: 127, fig. 4.13). Esto ha sido confirmado por la osteometría del húmero derecho de 15,3 cm de longitud, dos epífisis distales de húmeros con 4,7 y 4,6 cm (ancho) y el fémur izquierdo de $12 \mathrm{~cm}$ de longitud y su morfología robusta corresponde a un vultúrido.

\section{DisCUSIÓN}

Antes de iniciar la discusión ponemos en evidencia la rápida disminución de cóndores en nuestro medio en las dos últimas décadas y es motivo de preocupación. ${ }^{3}$ Este trabajo se concentrará en la discusión de cuatro puntos centrales: 1 . ¿Qué tipo de ritual evidencia el presente contexto y evento?; 2. ¿Este rito sería practicado por algún ayllu que tuviese como identidad al cóndor?; 3. ¿Cómo está referenciado el cóndor en la literatura arqueológica y etnohistórica?; y 4. ¿Cómo explicar la asociación del cóndor, la serpiente mítica y la cal?. Estas preguntas nos permiten hurgar aspectos de la teoría de la arqueología cognitiva. Es decir, la reconstrucción de las mentalidades andinas partiendo del registro arqueológico. De acuerdo al registro arqueológico, el contexto ritual de cóndores reportados en este artículo, sería el más antiguo de los conocidos hasta la actualidad.

El cóndor (Vultur gryphus) es un ave rapaz propio del área andina, carroñero, de gran tamaño y ha sido considerado una de las divinidades principales del panteón andino desde el periodo Arcaico Tardío y Formativo (Tello 1932, 1967; Yacovleff 1932; Carrión Cachot 1959; Kauffmann 1973; Bird 1964; Hocquenghem 1986; Bueno 1997, 2006; Asueta et al. 2003; Shady et al. 2004, 1999; Lumbreras 2007). El espécimen hallado en el Sector II, Unidad F-12, contexto P.M.6, Capa C, presenta el esqueleto de un cóndor casi completo, exceptuando sus garras y pico, posee dos marcas de corte en la cara externa articular del húmero derecho, así como huellas de fracturas antiguas postmortem. Al parecer los esqueletos parciales de otros cuatro vultúridos, también habrían sido desmembrados. Para discutir la hipótesis del desmembramiento de las alas y patas de los cóndores podemos basarnos en las marcas de cortes y fracturas postmortem en áreas articulares durante el arrancamiento de ligamentos y tendones adheridos a estas superficies óseas.

Para la caza del cóndor se empleaba la apaycha, liwi o riwi, especie de boleadora o manuports medianos utilizados especialmente para capturar el suri, un tipo de ñandú o avestruz (Antunez de Mayolo 1981: 34; Bertonio 1612:30). También se emplearon varios tipos de trampas como la llullama y la sipita, esta última era una cuerda con diversos lazos, en que el animal caía entrampado por el pescuezo al consumir la carroña utilizada como sebo. En tiempos actuales depredadores gauchos utilizan el ardid de colocarse como trampas humanas, para lo cual se colocan vísceras de cabras y fingen estar muertos, para así atraer y capturar al cóndor en tierra (Fig. 13). ${ }^{4}$

3 En 1973, el U.S. Fish and Wild Life Service (Agencia Federal para la Protección de Peces y Animales Salvajes) agregó al cóndor andino en la lista de especies amenazadas de extinción. Esta terrible experiencia ya ha sido vivida en Venezuela, donde en 1965 se vio volar el último cóndor de los Andes venezolanos y en la actualidad sólo cuenta con aproximadamente diez individuos, todos reintroducidos. En Colombia se encuentran alrededor de 50, en Ecuador no más de 75 y en Perú y Bolivia se sabe de una disminución marcadamente significativa (Asueta et al. 2003; ACOREMA 2010).

4 José María Arguedas (1941), en su libro Yawar Fiesta, narra el caso de la ceremonia de la caza del cóndor y su lucha ritual con el toro en la sierra de Ayacucho (Puquio), explicando que se trata del conflicto de dos mundos: el mundo andino profundo y el español criollo. Para cazar al cóndor, dos o tres hombres, muy de madrugada, suben a los cerros llevando carne de burro, cabra o res un poco descompuesta, cavan un hoyo y se esconden cubiertos con mantas mimetizadas en el suelo al lado de la carnada y esperan algunas horas, luego baja del firmamento un enorme cóndor que empieza a comer el sebo. En ese instante, los hombres rápidamente amarran las patas y garras del cóndor con gruesas cuerdas que se parece a la caza con sipita. Luego amarran la cabeza del animal y lo envuelven en un gran manto para ser transportado al pueblo e iniciar la ceremonia. Esta fiesta ocurre el día 28 de julio de cada año. 0 sea, en la estación de invierno. 


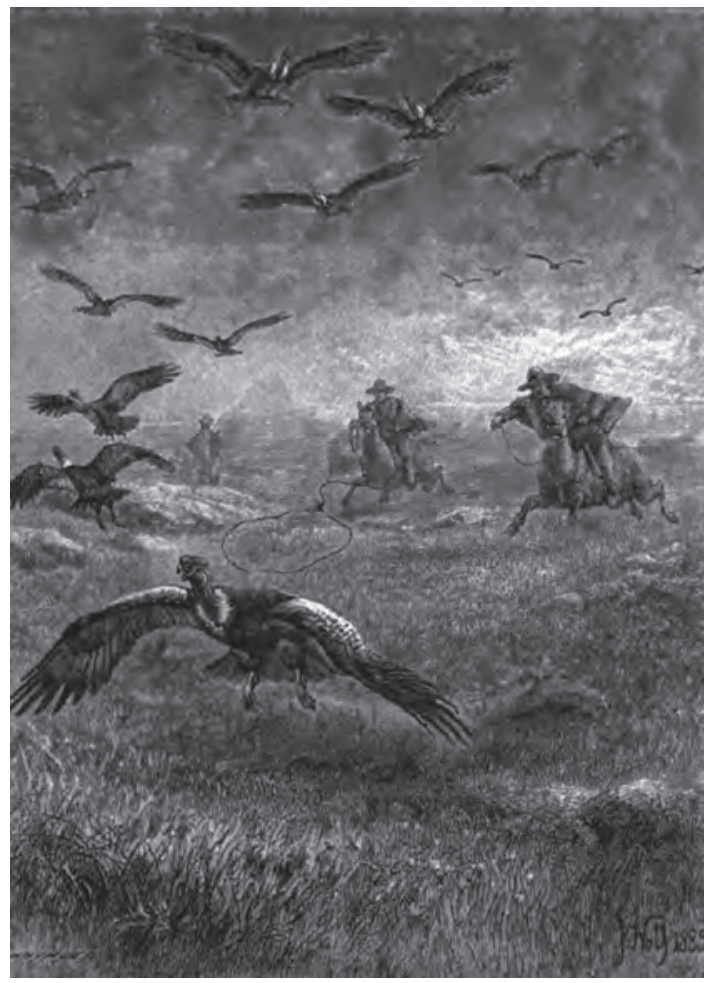

Figura 13 La caza del cóndor en el noroeste Argentino en el siglo XIX con lazos o sipita fue intensa por la creencia popular de tener propiedades curativas (dibujo de Edward Whymper 1892).

Para resolver las cuestiones arriba mencionadas hemos reunido algunos pasajes que nos permiten tener una idea de lo ocurrido con el caso bajo estudio. Veamos.

\section{Zooarqueología}

En 1946, Bird (1964) al excavar el famoso sitio de Huaca Prieta, valle de Chicama, descubre un tejido de algodón que tiene la figura del cóndor con las alas desplegadas y una serpiente en su estómago, surgiendo la hipótesis acerca de la existencia de un mito que narra la lucha entre ambos animales o de una transformación serpiente-cóndor que habría sido conocido desde el periodo Arcaico Tardío de la Costa Norte (Fig. 14).

Posteriormente, Shady (1999: 5) halló en contexto ritual de la esquina suroeste del anfiteatro de Caral una ofrenda de 32 flautas de huesos de alas de «pelicano» decoradas con figuras incisas y pintadas de rojo o negro, con representaciones de un ser ornitomorfo con rasgos de felinos o monos; y también de serpientes con rostros de ave y una representación bicéfala de ave y serpiente, atribuyéndole una antigüedad de 2500 a.C. (Shady et al. 2000: 2). De acuerdo a lo observado y por la ausencia de lagrimones nos inclinamos a considerar que el ave en referencia se aproxima a un cóndor, pues la característica del pico curvado no representa un ave marina sino más bien a un vultúrido con cola de serpiente (Fig. 15). ${ }^{5}$

Lumbreras (2007: 327), en la galería de las Ofrendas de Chavín, celdas 2 y 3, describe el hallazgo de cuatro huesos completos desarticulados de cóndor en área chamánica. Estos huesos largos, sin indicar el tipo óseo, estaban juntos y habían sido trabajados como preparando soportes para dagas o mango de un instrumento. Además afirma que el cóndor no es un animal fácil de cazar, y cuando se logra hacerlo, es siempre usado sólo para fines rituales, muchos de ellos muy rudos. En la figura 238, este mismo autor presenta una imagen de cóndor en actitud de vuelo y de cuyo cuello emerge una serpiente (Lumbreras Op. cit.: Fig. 16).

Debido a la presencia de marcas de corte en área articular y fracturas postmortem inferimos que el cóndor de Punta Blanca fue desmembrado. Por otro lado, en este mismo sitio, también se trataba con rudeza a los camélidos utilizados en el transporte debido al excesivo peso de la cal que transportaban a gran distancia, inferencia basada en las observaciones de las entesopatías y fracturas osificadas de las primeras falanges (Altamirano y Jave 2011).

5 La localización de la fosa circular en el centro del instrumento y la acumulación de una substancia «arcillosa» en la parte interna de la «caña», así como la ausencia de bocal en uno de sus bordes nos parece indicar que se trata de «phucunas», o sea, instrumentos de uso para inhalar alucinógenos en prácticas chamánicas, tal como aun lo practican en la Amazonía brasileña varias tribus Tupi. 


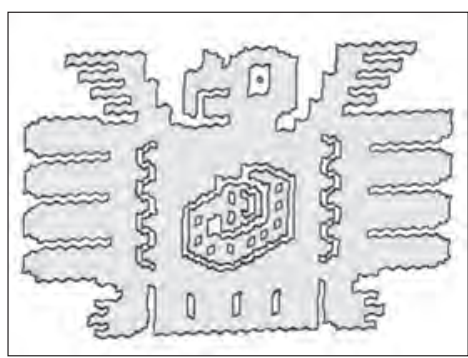

Figura 14. El cóndor de Huaca Prieta y la serpiente en su pecho-abdomen (Bird 1964).

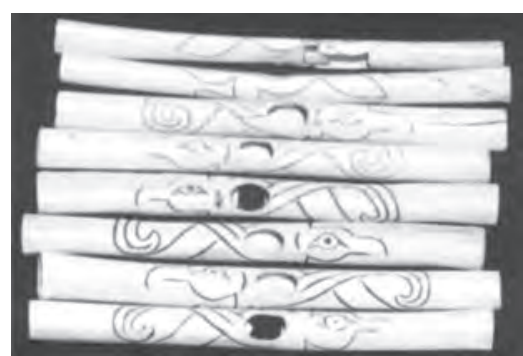

Figura 15. Flautas de huesos de «pelicano" con representaciones de cóndoresserpientes de Caral (Shady et al. 2000, Shady 1999).

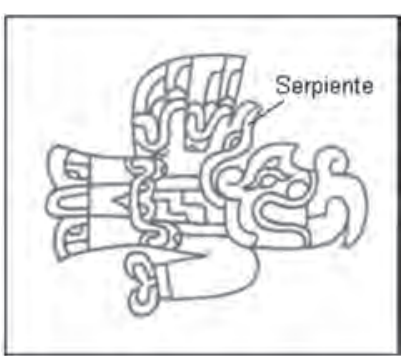

Figura 16. El cóndor y la serpiente en la mitología Chavín (Lumbreras 2007: 327, fig. 238).

Tello y Mejía Xesspe (1979: 484) descubren, en el relleno de la necrópolis de Wari Kayán, un entierro de cóndor o kunturi arropado con tejidos de algodón en el cateo № 259 (sp. 12/6263).

Maita y Casareto (2012) presentan el hallazgo de un cóndor y una llama en la cima de la pirámide Tello de Cajamarquilla, a escasos $35 \mathrm{~cm}$ de profundidad, asociado con un sacrifico humano. Sin embargo, se trata de una época posterior a los cóndores de Punta Blanca y no hacen referencia sobre el sexo del vultúrido, la forma de muerte ni las fracturas postmortem.

Otras especies de aves halladas en el sitio Cerro Punta Blanca son las gallinaceas o perdices (Nothoprocta pentlandii), Anatidae o pato joque (Cairina moschata), aynos o huashuas (Fulica ardesiaca), urpichas o pajaritos diversos (Passeriformes), gaviotas (Larus welcheri), Strigidae o lechuzas (Buho virginianus) y pingüino (Spheniscus humboldti). La mayoría de los huesos de aves presentan un color anaranjado, rojizo y marrón, indicando que fueron asados al aire libre. Sin embargo, en el caso de los cóndores sus huesos no indican cocción, consumo ni mordedura, el color es blanquecino por acción de la cal. Asimismo, para la captura de las aves del valle de Lurín es posible que se hayan utilizado trampas o redes de gran altura entre 5-7m de altura, más para aves grandes como el cóndor se requiere mayor destreza y valor, así como el uso de cuerdas y carnadas. ${ }^{6}$

Sobre la figurina cerámica -rota exprofesamente- y que denominamos como la «serpiente encrespada», caracterizada por sus ojos globosos y su dorso con crestas, se confirma que fue depositada como una ofrenda al cóndor. Al asociar estas dos evidencias: cóndor y serpiente mítica, hay una serie de datos que reafirman lo hallado en Punta Blanca, como es el caso de Huaca Prieta, Caral y Chavín. Asimismo, Alberto Bueno (2006: 77; 1998: 85-86) para un periodo más temprano refiere: «descubrimos rocas con petroglifos cuyos diseños concuerdan con las figuras identificadas en los textiles precerámicos de las tumbas de La Galgada, tales representaciones son serpientes sonrientes, aves y figuras geométricas, las que están directamente en relación estilística con los petroglifos del gran sitio Los Cóndores, en la quebrada Morín de la margen derecha del rio Chuquicara» (Fig. 17).

También Tomasto \& Makowski (2008) hallaron quenas de huesos de cóndor en contextos de cámaras funerarias de la Tablada de Lurín correspondientes al periodo Formativo Tardío (siglos II a.C.-I d.C.). Es posible sugerir que este instrumento musical de viento al ser de cóndor asumiría un papel simbólico de psicopompo, sacralidad y profunda tristeza, acompañando al difunto en el viaje al inframundo.

Asimismo, Urton (2008: 117, Fig. 32) registra en la zona de Misminay y Maras, Cusco, la constelación de la serpiente Amaru transformándose en cóndor, próximo a la constelación del Escorpión,

6 Los movimientos del cóndor de las alturas al litoral marino los realizaban en cualquier época del año en búsqueda de animales descompuestos como los lobos marinos y aves guaneras. En el área de lomas se le observan a gran altura buscando carroña y pernoctan en oquedades rocosas de difícil acceso donde viven en pareja y protegen a su cría. 
entre las constelaciones del dios Papa y la Colca (el granero). ${ }^{7}$ Este dato es importante porque permite confirmar nuestra hipótesis mitológica en tiempos actuales que deviene desde las ocupaciones de Huaca Prieta, La Galgada, Caral y Chavín. También Morales (2010) reproduce el petroglifo del sitio Quilca Rumi, valle de Higueras, Huánuco, descubierto por Javier Pulgar Vidal en la década de 1940, con la imagen de un cóndor estilizado envuelto en una banda circular oscura la que a su vez presenta pequeños círculos con punto que insinúa la forma de una serpiente. El ave se encuentra inmerso en una masa de numerosos puntos distribuidos regularmente, al parecer representaría la constelación del cóndor (Fig. 18).

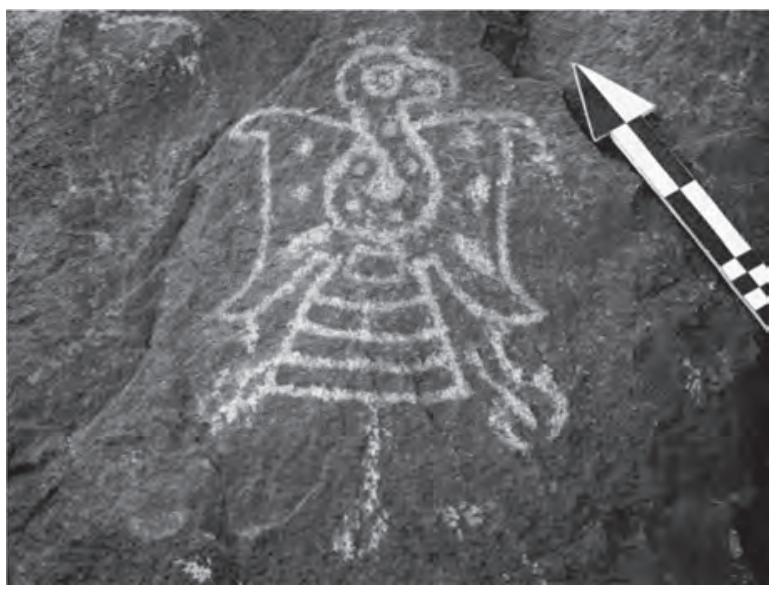

Figura 17. Petroglifo del cóndor, La Galgada. Foto cortesía del prof. Bueno Mendoza, 2012.

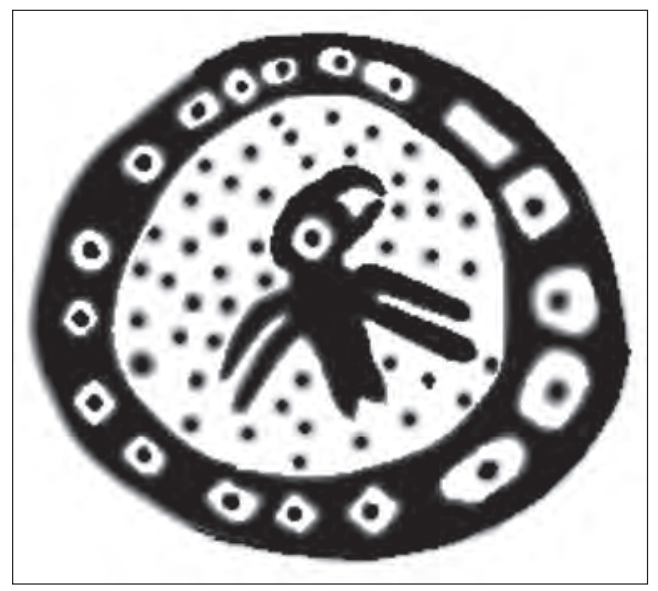

Figura 18. Petroglifo del valle de Higueras, Huánuco, con representación de cóndor (Morales 2010).

Patterson et al. (1982: 68) sostiene que durante el periodo Intermedio Temprano el valle de Lurín fue ocupado por dos formaciones sociales antagónicas y complementarias, los costeños y serranos, siendo la frontera cultural el área comprendida entre Cieneguilla y Sisicaya, y habiendo lugares donde convivieron ambos grupos para explotar los recursos naturales. Agrega que los grupos humanos del valle alto (serranos o upvalley) con cerámica marrón o rojo oscura ocuparon desde arriba de Sisicaya hasta las lomas de Atocongo. Concluye que los lomeros serían gente del valle alto y lo ocupaban en forma estacional solo en invierno para aprovechar los pastos para los camélidos y sus relaciones fueron pacíficas y cooperativas. Sin embargo, de acuerdo al análisis tipológico de la cerámica Punta Blanca (Ramos 2008) nosotros planteamos que el sitio Cerro Punta Blanca donde se explotaba intensamente la cal en una parte del año y la caza de venados y guanacos en invierno se habría practicado un modelo multiétnico y bidimensional de control del valle tanto alto cuanto bajo así como de larga distancia en dirección norte y sur. Por el norte se encuentra emparentada con la cerámica de Huachipa, valle del Rímac, y hacia el sur con Miramar de San Bartolo, Lapa Lapa en Chilca, Topará, valle de Chincha y Chongos, valle de Pisco, y que estas relaciones sociales no siempre fueron pacíficas.

Es evidente que en la cosmovisión de los mineros de Cerro Punta Blanca ya existía esta creencia de asociación cónd or-serpiente en el rito y en el mito andino. Estos hombres tenían una vida permanente en el área, que en épocas de invierno, entre junio y setiembre, cazaban venados (Odocoileus

7 Urton, Gary (2008). En el cruce de rumbos de la tierra y el cielo. Traducido por Alberto Miori. Editorial ABC, Lima. Es posible sugerir que para que se produzcan las lluvias era necesario que la serpiente ascendiese al Hanan Pacha, transportado por el cóndor y de allí daría vitalidad a la tierra, germinado a las plantas como un ciclo eterno. En la constelación de la llama, este baja del cielo para beber el gran diluvio o meganiño y la creación de la humanidad en Huarochiri (Zuidema 1982a, 1982b; Zuidema \& Urton 1977). 
virginianus) y guanacos (Lama guanicoe), mientras que en verano estarían explotando la cal e intercambiando este producto mineral con los pescadores y agricultores del valle de Pachacamac, Villa El Salvador, la Tablada de Lurín y El Panel, así como de diversos puntos desde Chongos, valle de Pisco, hasta Huachipa en el valle del Rímac. Sobre el material zooarqueológico se puede reconstruir la interacción de la vida cotidiana y ceremonial en relación a su economía, movimientos y divinidades basado en el control de solsticios y equinoccios (Fig. 19).

En el sitio tardío de Punkayán, margen izquierda de la cuenca del Santa Eulalia o Chaklla, sierra de Lima, se ha encontrado una huanca de cóndor a $3800 \mathrm{msnm}$ (Altamirano 2012). Se registra en el sector bajo, sobre una gran estructura circular de pirka, de $30 \mathrm{~m}$ de diámetro, de paredes anchas $(1,20 \mathrm{~m})$, con nichos y vanos, uno al Este y otro al Oeste. El ídolo, localizado en la parte norte, está conformado por tres grandes bloques intencionalmente colocados uno encima de otro. Las rocas, de origen volcánica, están talladas de forma cuadrangular y orientadas al Sur. La altura de la cabeza tiene $0,86 \mathrm{~m}$ por 1,40 $m$ de longitud. Posee una laja que sobresale en forma de pico. La cavidad ocular es una hendidura con la mirada al Oeste y, asimismo, parece tener nostril. El cuerpo es de forma cuadrangular ligeramente inclinado hacia el Oeste con 1,40 $\mathrm{m}$ de altura y 2,40 $\mathrm{m}$ de base. Descansa sobre una gruesa laja de $2 \mathrm{~m}$ de longitud. La altura total de la huanca es $3 \mathrm{~m}$. Las piedras fueron colocadas cuidadosamente uno encima de otro buscando la apariencia del ave. Debajo de la huanca hay una hornacina con huesos humanos aislados de entierro secundario y al parecer pertenecen a un hombre adulto. Si nuestro análisis es correcto esto podría indicarnos ser uno de los ancestros de los constructores del sitio. Los huachupampinos ya conocían esta roca y lo consideran todavía como un símbolo sagrado (Fig. 20).

También, sabemos que en Cajamarca, el sitio formativo hoy denominado como Cumbemayo, tenía como nombre original el de Cóndor qaqa. En suma, al correlacionar la época del ritual del cóndor y la estación de invierno es posible asumir que este evento haya ocurrido entre los meses de junio y setiembre cuando se realizaban la caza de cérvidos y guanacos en las lomas de Jatosisa. Asimismo, el empadre o reproducción de los cóndores sucede entre agosto y setiembre. Por otro lado, entre el solsticio de invierno ( 23 o 24 de junio) y el equinoccio de primavera ( 23 a 24 de setiembre) ocurrían grandes chacos que coincidían con sus fiestas regionales, permitiendo la concentración de diversos artesanos, pastores, lomeros, agricultores, pescadores, mineros y comerciantes, así como para los ritos de casamiento en estas fiestas notables que se celebraban anualmente en aquellos tiempos formativos. Todavía en Puquio, Ayacucho, en el Yawar fiesta el ritual de la caza del cóndor y la lucha con el toro ocurre el 28 de julio, fecha que encajaría entre nuestras predicciones de la época del rito.

\section{Etnohistoria}

Sobre la función ritual y mítica del cóndor hemos reunido algunos relatos tales como:

1. En el mito de Cuniraya Viracocha, se registra al cóndor en la huida de Cavillaca a Pachacamac, diciendo:

Figura 19. Hipótesis del ciclo anual de los habitantes de Cerro Punta Blanca, indicando que ellos ocupaban todo el año este piso ecológico. Los asteriscos indican las épocas posibles del ritual del cóndor.

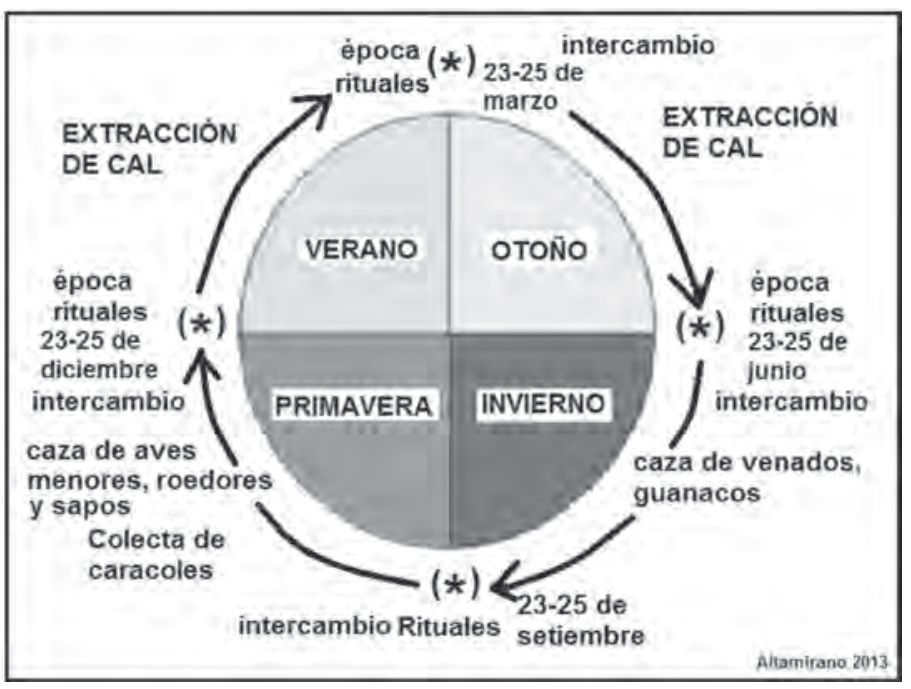




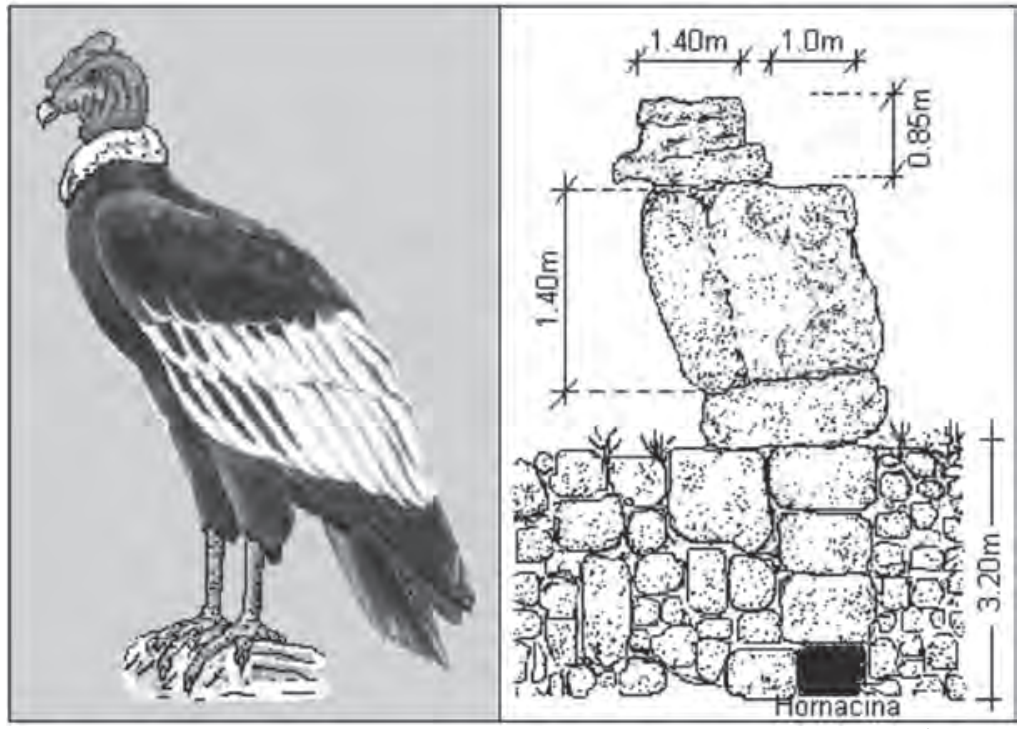

Figura 20. El huanca del cóndor, encima de una estructura circular del sector hurin (Altamirano 2012).

«Mi hermana /Cavillaca/ ha de verme, ha de aparecer, diciendo, llamándola y clamando, se alejó del sitio (Anchicocha). Y se encontró con un cóndor antiguo. Le preguntó al cóndor: Hermano, ¿dónde te encontraste con ella, con esa mujer?. Muy cerca de aquí - le contestó el cóndor - has de encontrarla. Y Cuniraya le dijo: Tendrás larga vida. Cuando mueran los animales salvajes, ya sea huanaco o vicuña, o cualquier otro animal, tú comerás su carne. Y si alguien te matara, ése, quién sea, también morirá. Así le dijo» (Ávila 2007 [1598]: 17).

2. Por otro lado, concerniente al mito del diluvio, menciona que los huarochiranos cuentan así:

«Lo que ellos cuentan es como sigue: en tiempos antiguos este mundo estuvo en peligro de desaparecer. Un llama macho (Yacana) que pastaba en una montaña con excelente yerba, sabía que la Madre Lago (el mar) había deseado (y decidido) desbordarse, caer como catarata. Este llama entristeció; se quejaba: in in diciendo, lloraba, y no comía. El dueño del llama, muy enojado, lo golpeó con una coronta de choclo: Come, perro - el dijo--, tú descansas sobre la mejor yerba. Entonces el llama, hablando como si fuera un hombre, le dijo: Ten mucho en cuenta y recuerda lo que voy a decirte ahora: de aquí a cinco días, el gran lago ha de llegar y todo el mundo acabará, asídijo, hablando. Y el dueño quedó espantado; le creyó. Iremos a cualquier sitio para escapar. Vamos a la montaña Huillcacoto, allí hemos de salvarnos; lleven comida para cinco días, ordenó, dijo. Y así, desde ese instante, el hombre se echó a caminar, llevando a su familia y al llama. Cuando estaba a punto de llegar al cerro Huillcacoto, encontró que todos los animales estaban reunidos: el puma, el zorro, el huanaco, el cóndor y todas las especies de animales. Y apenas hubo llegado el hombre, el agua empezó a caer en cataratas; entonces allí, apretándose mucho, estuvieron hombres y animales de todas partes, en el cerro de Huillcacoto, en un pequeño espacio, sólo en la punta, hasta donde el agua no pudo alcanzar. Pero el agua logró tocar el extremo del rabo del zorro y lo mojó, por eso quedó ennegrecido. Y cumplidos los cinco días, el agua empezó a descender, se secó; y la parte seca creció; el mar se retiró más, y retirándose y secándose mató a todos los hombres. Solo ése de la montaña vivió y con él volvió a aumentar la gente, y por él existe el hombre hasta hoy» (Ávila 2007 [1598]: 23).

3. El extirpador Francisco de Ávila, afirma que cuando los huiracochas (españoles) estuvieron a punto de aparecer, Cuniraya fue hacia el Cuzco. Y entonces hablaron, él y el inca Huayna Capac, entre ellos. Cuniraya le dijo: Vamos, hijo, al Titicaca; allí te haré saber lo que soy. Y luego, diciendo, dijo: Inca, da orden a tu gente, a los brujos, a todos los que tienen sabiduría, para que poda- 
mos enviarlos a las regiones bajas, a todas. Apenas habló Cuniraya, inmediatamente, el Inca dio la orden. Y así, algunos de los hombres (¿emisarios?) dijeron: Yo fui creado por el cóndor. Otros dijeron: Yo soy hijo del halcón, y otros: Yo soy el ave golondrina. A todos ellos les ordenó (el inca): Id hacia las regiones bajas y allí decid a todos los padres: «Me envía vuestro hijo; dice que le remitas a una de sus hermanas». Así hablarán. De ese modo les ordenó. Entonces, el hombre que fue creado por la golondrina y los otros partieron, habiéndoseles dado sólo cinco días de plazo para volver (Ávila 2007 [1598]: 83).

4. También el autor citado, se refiere a la astronomía andina y afirma que hay tres estrellas que brillan casi juntas. A ellas les llaman Cóndor, y otras les dan el nombre de Gallinazo y de Halcón. Y cuando las Cabrillas aparecen de gran tamaño, dicen: Este año vamos a tener maduración excelente de los frutos, pero cuando se presentan muy pequeñitas, dicen: vamos a sufrir. A las estrellas que brillan moviéndose y en conjunto las llaman Pichcaconqui. Pero a las que vienen grandes, muy grandes, las llaman Pocochorac, Huillcahuarac, Canchahuarac, así las nombran. En la antigüedad, una parte de la gente rendía culto a estas estrellas grandes. Ellas crean y mandan, decían. Otros veneraban a estos huacas cuando ya aparecían; pasaban la noche sin dormir ningún instante: Desde aquí voy a hacer que venza, afirmaban (Ávila 2007 [1598]: 153). De estas cuatro referencias se desprende que el cóndor actúa en la mitología de la sierra de Lima como un héroe cosmológico, mensajero y astronómico (padre de Pariacaca), ser totémico y genealógico, dando origen a diversos ayllus.

Tello (1923, 1967: 173) transcribe sobre el cóndor entre los Collas, siguiendo la lectura de Rigoberto Paredes (1920: 191). Menciona que el vultúrido era considerado entre los Kollas, como después entre los blancos, el rey de las aves; por eso le llamaban siempre Mallku Kunturi, atribuyéndole el don de trasmitir la fuerza que posee al que se ponía bajo su inmediata protección. El cóndor y el jaguar han sido los dioses tutelares de los indios y hoy mismo los miran con religioso respeto. El indio que degüella a un cordero o buey ofrece la sangre caliente al cóndor y para que quede constancia de su ofrenda rocía con ella la parte exterior de las paredes de su vivienda.

5. En el pueblo de Huamantanga, Canta, el licenciado Don Pedro de Quijano Benellos recibe la visita del indígena Fernando Carhuachín el 8 de abril de 1656 y registra una ceremonia de cura del mal de corazón:

«[...] Fernando Caruachin declara y confiessa ser guari del pueblo de San Pedro de Quipan anexo de esta doctrina de Guamantanga del Aillo de Allauca. Dijo que arriva de la capilla que solia ser del Santo Cristo por un lado de ella esta una lagunilla en medio de la qual le esta levantada una piedra llamada Guanca a la qual adoran los mas de a que este pueblo de Guamantanga y que una india nombrada Jauja María, viuda natural del pueblo de Rauma y residente en este pueblo de Guamantanga el pidió y rrogó a este que declara abra treze años poco más o menos que tenía una hija enferma de mal de corazón llamada Ana que entonces tenía de quatro a zinco años y oy esta cassada con un yndio cantor destepuevlo que no se acuerda de su nombre más de que es de el aillo de Ziguas que fuese con ella este declarante a la dicha laguna y alli pidiese y rogasse a Dios que es la dicha piedra nombrada Guanca que le diese salud y en esta conformidad fue este declarante con la dicha muchacha mui de mañana y puesto en pie juntando y abriendo las manos la adoro diziendo padre y dios mio tu quitaste la salud a esta pobre dadle vida y quitadle el achaque y a estas razones la asperseo y echó coca en hoja y luego le ofreció un corderito de llama muerto llegando se la dicha piedra y poniendolo al pie de ella a causa de ser seca y no tener agua la dicha laguna y con un poco de sebo de llama lo quemó juntamente con el dicho cordero haciendo sacrificio de ello a la dich a piedra encendiendo y echó con una brasa de candela hasta que todo ello se hizo zeniza y mientras se quemava lo referido estava en oración pidiendole la salud de la dicha muchacha y diciendole a la dicha piedra que por sus antepasados la avian adorado tambien la adorava este declarante ofreciendole en sacrificio como ellos los referido a lo qual hizo que la dicha muchacha se llegase a la dicha piedra y con esto volvieron y se llevó a su madre diciendo que y estava buena su hija y que diese a beber sangre de cóndor y que se lo dio a beber por una vez que a si se lo dijo su madre de la dicha muchacha y que quien dara razón de lo demás y de las guacas del pueblo de Guamantanga nombrada Tiilla Guacho que esta presa en la cárcel de este dicho pueblo de donde es natural y que este declarante por no ser de este pueblo no sabe mas de lo referido» (León Fernández 2009: 235). 
Asimismo, agrega:

"Y que asimismo le mingo a este que declara otra india del pueblo de Guamantanga nombrada Illa y que al presentar está presa y que es viuda lo cual fue a casa de este que declara en compañía de dos hijas suyas llamadas la una Catalina y la otra no save su nombre ahora dos meses y medio y que le pidieron que hiciese que la hija mayor que es la dicha Chata//lina no anduviese inquieta con españoles y que la otra menor se la sanase de un mal de corazón que padecia y que este declarante les mandó y de o por medio que matasen un perro y le dice a beber la sangre a la que padecia el dicho mal de corazón y que sino le quitase hiciese matar un cóndor y sacándole el corazón se lo diese a comer y para que la otra se quitase y casa se le pidió unos pocos cavellos y con ellos pelos de zorro y de león y se le entregó todo a la dicha su madre...»(León Fernández Op. cit.: 237-38).

De estas dos últimas citas se desprende que el cóndor actúa en los ritos de la sierra de Lima y Puno para recibir la gracia divina en momentos de flaqueza y para obtener soluciones beneficiosas frente a las adversidades de la vida, a los dolores del alma y la protección del hogar. Es posible que la sangre del cóndor en el Cerro Punta Blanca haya sido utilizada con fines curativos y búsqueda de parabién contra las enfermedades y circunstancias adversas, pues en el análisis de la osamenta humana del sitio hemos encontrado diversas enfermedades como la treponematosis (del tipo buba o pian) ${ }^{8}$ y también hay evidencias de fracturas producto de violencia.

En suma, la serpiente representa el mundo del Uku Pacha, el culto al agua, los canales, fertilidad, femenino y reproducción. Mientras que el cóndor representa la fuerza del Hanan Pacha, el culto al viento Kon, el Sol, el día, la luz, masculino y al bajar a la tierra se produce el contacto entre ambos mundos. Así el cóndor se convierte en el principal mensajero entre los dioses del Hanan pacha y del Uku pacha. Es el arquetipo y símbolo sagrado de los wamanis, uywiri, jirkas y ñawpa machus. Por estos datos consideramos que el presente contexto ritual constituye el simbolismo de un tinkuy o el encuentro de ambos mundos, que el sacerdote o chamán de Cerro Punta Blanca trató de invocar el agua o lluvias en momentos de extrema aridez, tal como se desprende del análisis de este estudio.

\section{CONCLUSIONES}

1. El presente contexto ritual nos permite inferir que los antiguos mineros del Cerro Punta Blanca, valle de Lurín, estaban practicando ceremonias donde el cóndor macho era el principal elemento relacionado al Hanan Pacha y su contraparte la serpiente relacionada al inframundo y al culto al agua (Uku Pacha).

2. Los huesos de los cóndores fueron arrancados postmortem durante un tipo de ritual especializado. Dos hipótesis surgen al respecto: una, sería que era parte de un rito acíclico y su estrecha relación con la cura de males del corazón o problemas del alma que estarían padeciendo los hombres de Punta Blanca. La segunda refiere que estos rituales eran practicados en fiestas periódicas o cíclicas, permitieron la cohesión social entre los hombres del valle alto y del valle bajo, reafirmando los intereses de los miembros del grupo en cuanto a la explotación, almacenamiento y redistribución de la cal en la región.

3. Al asociarse con la figurina de cerámica que representa un réptil mítico, que consideramos una «serpiente de ojos globosos y encrespada», nos permite sugerir la existencia de un mito de lucha, encuentro o tinkuy entre el cóndor y el réptil en la invocación del agua.

8 Vradenburg et al. (Ms.) afirma que durante fines del Horizonte Temprano de la costa central, la treponematosis, una enfermedad venérea propia de la especie humana, se expandió rápidamente en los diversos asentamientos de la tradición Banco sobre Rojo. Este mal ya era conocida como Huanthi en Huarochiri y tal vez se «curaba» bebiendo la sangre del cóndor. 
4. El cóndor simboliza la fuerza de los dioses del Hanan Pacha y se encuentra asociado constantemente con la serpiente para la invocación de lluvias. Pues el cóndor aparece ingiriendo a la serpiente, indicando que este es el portador del mensaje de los habitantes y el inicio de las festividades andinas que ocurrían en la estación de invierno entre agosto y setiembre como el caso del Yawar fiesta.

\section{Agradecimientos}

A la Empresa UNACEM S.A.A. por haber financiado los trabajos de campo durante las temporadas 2004 y 2006-7. Al Lic. Ponciano Paredes por haber dirigido las dos temporadas, a los arqueólogos Casimiro Chávez Alarco, Mónica Suárez Ubillus, Max Salazar Vivanco, y la pléyade de profesionales y estudiantes de la Universidad Nacional Federico Villarreal y la Universidad Nacional San Luis Gonzaga de Ica durante los trabajos de campo y gabinete. Finalmente, nuestro agradecimiento al Dr. Alberto Bueno Mendoza quién nos proporcionó gentilmente la foto № 17, al Lic. Daniel Morales Chocano por sus valiosas sugerencias en campo, a la Lic. Julia López y a la señora Cristiane Patricio dos Santos por el apoyo en el procesamiento de la información de los materiales faunísticos.

\section{BiBLIOGRAFÍA}

ACOREMA

2010 Especies amenazadas de la zona marino costera de Pisco. Guía para docentes. $2^{\mathrm{a}}$ edición. [En línea], disponible en <http://www.delphinschutz.org/informationsmaterial/schutzprojekt-peru/Teacher_ Guide_Second_edition_2010.pdf>, [acceso el 22 de enero de 2013]. Lima.

ADARO, L y BENAVENTE, M.A.

1993 Identificación de indicadores óseos de camélidos sudamericanos. Santiago: Universidad de Chile, Escuela de Medicina Veterinaria.

ALTAMIRANO, A.

2012 «De la huanca a lo cognitivo: el sitio arqueológico tardío de Punkayán, distrito de Huachupampa, Huarochirí, Perú». P. van Dalen (editor), Arqueología de la sierra de Lima, Lima. En prensa.

1995 Función ritual de camélidos en la costa norte del Perú: sacrificios de Pacatnamú. Disertación para optar el Grado Académico de Magister en Arqueología, PUC, Lima. 149 p. [Inédito].

1983 «Pesca y utilización del camélido en Manchán, Casma». Boletín de Lima N³ 30: 62-74. Lima.

ALTAMIRANO, A.J. y C.N. JAVE

2011 «Estrés por esfuerzo repetitivo en camélidos del Formativo Tardío del valle de Lurín: sitio Cerro Punta Blanca». Programa y resúmenes de la IV Reunión de la Asociación de Paleopatología en Sudamérica, Resumen, p. 81, del 2 al 5 de noviembre de 2011, Lima.

ALTAMIRANO, A. et al.

1979 «Guía osteológica de camélidos sudamericanos». Serie Investigaciones № 4, UNMSM, Lima.

ANTUNEZ DE MAYOLO, S.

1981 La nutrición en el antiguo Perú. Lima: Banco de Reserva de Perú, Oficina Numismática.

ARGUEDAS, J.M.

1945 «Yawar Fiesta». Revista Americana, año XIV, № 156, Buenos Aires.

ARRIAGA, José de

1920 [1616]. La extirpación de idolatría en el Perú. Colección de libros y documentos referentes a la Historia del Perú. Vol. 1, 2ª edición, Lima: Servicio editorial Heudoxio Urteaga y C. Romero.

2003 Relevamiento de asentamientos de cóndores en zonas aledañas a Río Turbio, Informe Segunda Etapa. Informe Técnico Rectorado UNPA. Pp: 1 - 31. Río Gallegos, Santa Cruz.

AVILA, Francisco de

2007 [1598]. Dioses y hombres de Huarochirí. Traducción de José María Arguedas. Lima: Universidad Antonio Ruiz de Montoya, Jesuitas. 
BAUMEL, J.J., A.S. KING, J.E. BREAZILE, H.E. EVANS y J.C. VANDEN BERGE

1993 Handbook of avium anatomy. Nomina anatómica avium. Segunda edición. Publications of the Nuttall Ornithological Club, 23: 45-132. Cambridge, Massachussets.

BENAVENTE, M.A., L. ADARO, P. GECELE y C. CUNAZZA

1993 Contribución a la determinación especies animales en arqueología: familia Camelidae y Taruca del Norte. Santiago: Universidad de Chile, Vicerrectoría Académica y Estudiantil, Departamento Técnica de Investigación, Serie de Programa de Desarrollo, vol. II.

BERTONIO, Ludovico

1612 Vocabulario de la lengua aymara, Juli.

BIRD, J.

1964 «El arte precerámico de Huaca Prieta». Revista Peruana de Cultura, tomo I, Lima.

BRACK EGG, A.J.

1974 «Los vertebrados de las lomas costeras del Perú». Anales Científicos 12 (3-4): 85-92. Lima: Universidad Nacional Agraria La Molina.

1988 «La fauna». En: Manfer y Juan Mejía Baca (eds) Gran Geografía del Perú. Naturaleza y Hombre T. III: 1-247. 3ra. edición. México.

BUENO MENDOZA, A.

1982 «El antiguo valle de Pachacamac: espacio, tiempo y cultura». Rev. Boletín de Lima, № 24, 25 y 26, Lima (Separata de 67 pp.).

1997 «Los Cóndores y La Galgada: petroglifos como textos gráficos». En: Rev. Espacio, № 36, Lima.

1998 «Petroglifos en la quebrada Morín, Calipuy bajo y la Galgada, Cañón del rio Chuquicara». En: Luis Santa María Paredes (ed.) Rev. Santiago de Chuco y el Patrón Santiago: 7-14 Lima: Universidad Alas Peruanas.

2007 «Petroglifos en la quebrada Morín y La Galgada; de los textos gráficos al mito etiológico». Investigaciones Sociales № 17: 67-90, Lima: UNMSM.

BURGER, R.

1995 Chavin and the Origins of Andean Civilization. Londres: Thames and Hudson.

1993 Emergencia de la civilización en los Andes. Ensayos de interpretación. Lima: UNMSM.

CÁRDENAS, M.

1999 Tablada de Lurín, excavaciones 1958-1989. Patrones funerarios. Tomo I. Lima: IRA-PUCP.

CARRION CACHOT, R.

1959 La religión en el antiguo Perú. Lima: Talleres Gráficos de Tipología Peruana.

DUVIOLS, P.

1974-76 «Un Petite chronique retrovee: errors, ritos, supersticiones y ceremonias de los indios de la provincia de Chinchaycocha y otras del Perú». Journal de la Societe des Americanistes 63: 275-286.

GOEPFERT, N.

2008 «Ofrendas y sacrificios de animales en la cultura Mochica: el ejemplo de la Plataforma Uhle, Complejo Arqueológico Huacas del Sol y de la Luna». En: LJ Castillo, H Bernier, G Lockard y J Rucabado (editores), Arqueología Mochica nuevos enfoques. pp. 231-244. Lima: PUCP - IFEA.

GONZALES HOLGUIN, Diego

1987 [1608] Vocabulario de la Lengua General de todo el Perú llamada lengua Qquechua. Lima: UNMSM.

HAEMIG, P.D.

2005 Ecología de los Cóndores. [en línea] Disponible en: <http://www.ecologia.info/condor.htm>.

HOCQUENGHEM, A.M.

1986 Iconografía Mochica. Lima: PUCP, 280 p.

1983 Iconografía Moche. Berlín: Latinamerika Institut der Frein Universitat.

HOWARD, $\mathrm{H}$.

1968 «Limb measurements of the extinct vulture», Coragyps occidentalis, with a description of a new subspecies. Papers Archeol. Sot. New Mexico, vol. 1:115-127.

HUERTAS, L.

1981 La religión en una sociedad rural andina (siglo XVII). Ayacucho: Universidad Nacional San Cristóbal de Huamanga. 
JIMÉNEZ BORJA, A.

2009 [1951] «Instrumentos musicales peruanos». Ensayos. Arturo Jiménez Borja. pp: 65-104. Lima: INC. JIMÉNEZ, M.

2002 Lomas de Atocongo, valle de Lurín: Una aproximación a las ocupaciones tempranas en el Periodo Formativo. Tesis de Licenciatura. Facultad de Letras y Ciencias Humanas. Pontificia Universidad Católica del Perú, Lima.

JEREZ, Fernando de

1938 [1532] «Conquista del Perú y Provincia del Cuzco». En Julio Le Riverend (ed.) Crónicas de la Conquista del Perú, pp. 27-124. México: Editorial Nueva España.

KAUFFMANN DOIG, F.

1973 Manual de arqueología peruana. Lima: Ediciones Peisa.

KLEMENC, S

1997 The Flight of the Condor. [en línea] Disponible en: <http://www.kondor.de/condor/tanz_e.html>.

KOEPCKE, M.

1970 The bird of the Department of Lima, Perú. Wynnewood: Livingston Publishing Company. 144 p.

LEÓN FERNÁNDEZ, D.

2009 Evangelización y control social a la doctrina de nuestra señora de la limpia, purísima e inmaculada concepción de Canta, siglos XVI y XVII. Lima: UNMSM.

LUMBRERAS, L.G.

2007 Chavin, excavaciones arqueológicas. Dos tomos. Lima: Universidad Alas Peruanas.

MAGUIÑA, A. y P. PAREDES

2009 «El Panel: patrón de enterramiento, análisis del material y su correlación estilística en la costa central del Perú». En: RL Burger y K Makowski (eds.), Arqueología del período formativo en la cuenca baja de Lurín, pp. 283-318, Lima: PUCP.

MAITA, P. y D. CASARETO

2012 «Offering animals before human sacrifice: Sequence of sacrifice and burial of Condor (Vultur gryphus) and llama (Lama glama) in Cajamarquilla, Ancient Peru». Congreso de Archaeozoological del ICAZ, París.Disponible en:<http://www.alexandriaarchive.org/bonecommons/items/show/1350> [acceso el 2 de enero de 2013].

MÁLAGA, A., R. MATOS, E. PIRES-FERREIRA y J. WHEELER

1976 Sobre el laboratorio de Paleoetnozoología. Lima: Gabinete de Arqueología, UNMSM.

MAKOWSKI, K.

2002 «Power and social ranking at the end of the Formative Period: The lower Lurin valley cemeteries». En: W. Isbell y H. Silverman (eds.) Andean Archaeology I. Variations in sociopolitical organization, pp. 89-120, Nueva York: Kluwer Academic \& Plenum Publishers.

2002 «Poder y estatus social a fines del Periodo Formativo: los cementerios del valle bajo de Lurín». [En línea] Facultad de Letras y Ciencias Humanas, PCUP. Disponible en < http://facultad.pucp.edu.pe/ letras-ciencias-humanas/patl/docs/poder_estatus_social_fines_periodo_formativo.pdf>, [acceso el 21 de enero de 2013], Lima.

MAMELI, L.

2003 La gestión del recurso avifaunístico por las poblaciones canoeras del archipiélago Fueguino. Tesis doctoral en arqueología, UAB, Barcelona, España.

MILLONES, Luis y Renata MAYER

2012 La fauna sagrada de Huarochiri. Lima: IEP, IFEA.

OKA, S. y H. OGAWA

1984 «The distribution of lomas vegetation and its climatic environments along the Pacific coast of Peru». Geographical reports of Tokyo Metropolitan University 19: 113-125. Tokio.

OLIVA, A.

1985 [1598] Historia del reino y provincia del Perú y de sus incas reyes Descubrimiento. Lima: Juan F. Pazos y Luis Varela y Orbegoso Imp. y Librería San Pedro. 
PALACIOS, J.

1988 «La secuencia de la cerámica temprana del valle de Lima en Huachipa». Gaceta Arqueológica Andina 16: 13-24. Lima.

2004 Informe preliminar de la colección cerámica del sector III, sitio arqueológico Cerro Punta Blanca, valle de Lurín. Inédito.

PAREDES, P.

1984 «El Panel (Pachacamac): nuevo tipo de enterramiento». En: Gaceta Arqueológica Andina 10: 9-8, Lima.

PAREDES, R.

1920 Mitos, supersticiones y supervivencias populares de Bolivia. La Paz: Ediciones Isla.

PATTERSON, T.C., J.P. McCARTHY R.A. DUNN

1982 «Polities in the Lurin Valley, Peru, during the early Intermediate Period». Ñawpa Pacha 20: 61-82.

POLO DE ONDEGARDO, Juan

1916 [1571] Relación de los fundamentos acerca del notable daño que resulta de no guardar a los indios y a sus fueros. Junio 26 de 1571.Colección H. Urteaga-Romero, tomo III, Lima.

PULGAR VIDAL, J.

1987 Geografía del Perú: las ocho regiones naturales del Perú. Lima: Peisa.

RAMOS, J.A.

2008 Análisis y descripción de la cerámica de Cerro Punta Blanca. Inédito.

REA, A.M.

1986 «Black vultures and human victims archaeological evidences from Pacatnamu». Pacatnamu papers Vol. 1: 139-44. Los Angeles.

RODRIGUEZ, C.

1998 «L'Étude archéozologique de sites formatifs au Perou: l'exemple de Tablada de Lurín». Actes du XIII Congrés de l'Union Internationale des Sciences Prehistoriques et Protohistoriques. Forli, 8-14 setiembre de 1996, vol V.

ROSTWOROWSKI, M.

1981 Recursos naturales renovables y pesca, siglos XVI-XVII. Lima: IEP.

1975 «Pescadores, artesanos y mercaderes costeños en el Perú Prehispánico». Revista del Museo Nacional 41: 311-349, Lima.

SHADY, R.

1999 «Las flautas de Caral: el conjunto musical más antiguo de América». Boletín del Museo de Arqueología y Antropología, 2(10): 1-5. Lima: UNMSM.

SHADY, R., M. PRADO, C. LEIVA, J. MORENO, C. JIMENEZ y C. LLIMPE

2000 «Las flautas de Caral-Supe: aproximaciones al estudio acústico-arqueológico del conjunto más antiguos de América». Boletín del Museo de Arqueología y Antropología, 3(11): 2-9, Lima: UNMSM.

STOTHERT, K.S.

1980 «The Villa El Salvador site and the beginning of the early intermediate period in the Lurin valley, Peru». En: Journal of field archaeology 7(3), Boston.

TELLO, J.C.

1981 Antiguo Perú, primera época. Agosto. Lima: Editorial Facsimilar.

1967 Páginas escogidas. Selección y prólogo de Toribio Mejía Xesspe, UNSMSM: Lima. 241p.

1923 «La religión en el antiguo Perú: Wiracocha». Revista INCA, 1(1): 93-320, Lima.

TELLO, J.C. y T. MEJÍA XESSPE

1979 Paracas. II Parte: Cavernas y Necrópolis. Lima: UNMSM.

TOLEDO, Francisco de

1940 [1570] Informaciones sobre los Incas. Madrid.

TOMASTO, E.C. y K. MAKOWSKI

2008 «El rol de los niños en una sociedad del Período Intermedio Temprano». [En línea] Facultad de Letras y Ciencias Humanas, PCUP. Disponible en <http://patl.pucp.edu.pe/sites/patl.pucp.edu.pe/ files/Articulo_Makowski_tomasto.pdf>, [acceso el 21 de enero de 2013], Lima. 
TOMOEDA, $\mathrm{H}$.

1993 «Los ritos contemporáneos de camélidos y la ceremonia de la citua». En: Senri Ethnological Studies 37: 289-306, Osaka.

TOVAR, 0.

1972 «Revisión de las especies peruanas del género Festuca, Gramineae». Memorias del Museo de Historia Natural «Javier Prado». N 16, Lima: UNMSM.

TURNER, V.W.

1973 Simbolismo y ritual. Lima: Departamento de Ciencias Sociales, PUCP.

URTON, G.

2008 En el cruce de rumbos de la tierra y el cielo. Traducción Alberto Miori, Lima: eds. ABC.

1981 «Animals and astronomy in the quechua universe». En: American Philosophical Society Proceeding vol. 125 (2): 109-127.

VALDIZAN, H. y A. MALDONADO

1922 La medicina popular, tomo I. Contribución al folklore médico del Perú. Lima: Imprenta Torres Aguirre.

VAN GENNEP, A.

1960 [1909] The rites of Passage. Chicago: University of Chicago Press.

VÁSQUEZ, V.F. y T.T. ROSALES

1999 «Zooarqueología: Teoría y práctica». Serie Zooarqueología, No. 2, Arqueobios, Trujillo, 159 p.

VON DEN DRIESCH, G.

1976 A guide to the measurement of animal bones from archaeological sites. Harvard University, Peabody Museum of Archaeology and Cambridge, MA: Peabody Museum, Bulletin 1.

VRADENBURG, J., R. BENFER, K. MAKOSWKI, y M. DELGADO

Ms. A Consideration of the role of treponematosis in the development of prehistoric peruvian cultures on the central coast. En: R.L. Burger \& M. Makowski (eds.) Arqueología del período formativo en la Cuenca baja de Lurín. Fondo de la PUCP, Lima (2009). Vol. I.

WHITE, T.

1953 «A method for calculating the dietary percentage of various food animals utilized by aboriginal people». American Antiquity 18: 396-98.

WING, E.

1972 «Utilization of animal resources in the Peruvian Andes». En: S. Izumi y K. Terada (eds.) Andes 4, excavations at Kotosh, 1963-1966, pp. 327-52. Tokyo: University of Tokyo Press.

WHYMPER, E

1892 Viajes por los grandes Andes del Ecuador. Nueva York.

YACOVLEFF, E.

1932 «Las falcónidas en el arte y en las creencias de los antiguos peruanos». Revista del Museo Nacional, tomo I: 35-111, Lima.

ZARATE, Agustín de

1947 [1555] «Historia del descubrimiento y conquista de la provincia del Perú y de las guerras y las cosas señaladas en ella, [...]» En: Biblioteca de Autores Españoles 26: 319-48. Madrid: Eds. Atlas.

ZUIDEMA, T.R.

1982a «Bureacracy and systematic knowledge in Andean Civilization». En: G.A. Collier, R.I. Rosaldo, J.D. Wirth (eds.) The Inca and Aztec states 1400-1800. New York.

$1982 \mathrm{~b}$ «Myth and history in ancient Peru». En: The Logic of Culture. Advances in structural theory and methods. I. Rossi and contributors. New York.

1983 «Llama sacrificies and computations: roots of the Inca calendar in Huari-Tiahuanaco Culture». En: Acts of the Congress on Ethno-Astronomy, Washington DC.

ZUIDEMA, T.R. y G. URTON

1977 «La constelación de la llama en los Andes Peruanos: su importancia para el calendario andino». Allpanchis 9: 59-119. Cusco: Instituto Pastoral Andina. 